\title{
Language Practices and Linguistic Ideologies in Suriname: Results from a School Survey
}

\author{
Isabelle Léglise and Bettina Migge
}

\section{$1 \quad$ Introduction}

The population of the Guiana plateau is characterised by multilingualism and the Republic of Suriname is no exception to this. Apart from the country's official language, Dutch, and the national lingua franca, Sranantongo, more than twenty other languages belonging to several distinct language families are spoken by less than half a million people. Some of these languages such as Saamaka and Sarnámi have quite significant speaker communities while others like Mawayana currently have less than ten speakers. ${ }^{1}$ While many of the languages currently spoken in Suriname have been part of the Surinamese linguistic landscape for a long time, others came to Suriname as part of more recent patterns of mobility. Languages with a long history in Suriname are the Amerindian languages Lokono (Arawak), Kari'na, Trio, and Wayana, the creole languages Saamaka, Ndyuka, Matawai, Pamaka, Kwinti, and Sranantongo, and the Asian-Surinamese languages Sarnámi, Javanese, and Hakka Chinese. In recent years, languages spoken in other countries in the region such as Brazilian Portuguese, Guyanese English, Guyanese Creole, Spanish, French, Haitian Creole (see Laëthier this volume) and from further afield such as varieties of five Chinese dialect groups (Northern Chinese, $\mathrm{Wu}, \mathrm{Min}$, Yue, and Kejia, see Tjon Sie Fat this volume) have been added to Suriname's linguistic landscape due to their speakers' increasing involvement in Suriname.

Suriname's linguistic diversity is little appreciated locally. Since independence in 1975, successive governments have pursued a policy of linguistic assimilation to Dutch with the result that nowadays, "[a] large proportion of the population not only speaks Dutch, but speaks it as their first and best language" (St-Hilaire 2001: 1012). Increased urbanisation, improvements in the infrastructure and expansion of the education system prior to Suriname's

1 Carlin (2001: 226) mentions four Amerindian languages, Akuriyo, Sikiïyana, Tunayana, and Mawayana whose speaker numbers are very low, ranging from between 5 to 10 speakers.

(C) ISABELLE LÉGLISE AND BETTINA MIGGE, 2015 | DOI 10.1163/9789004280120_003

This is an open access chapter distributed under the terms of the Creative Commons Attribution-

Noncommercial 3.0 Unported (CC-BY-NC 3.0) License. 
civil war and in the new millennium have acted as important catalysts for this policy. Yet, assimilation to Dutch is by no means complete. St-Hilaire, for instance, argues that different population groups recognised within Suriname-Afro-Surinamese Creoles, East Indians, Javanese, Maroons, but also Amerindians and Chinese-have followed different paths of adaptation. At least until the 1950s, Afro-Surinamese Creoles "had wholeheartedly accepted assimilation to Dutch as a group ideal" (St-Hilaire 2001: 1005). In the 1950s and 1960s the cultural nationalist movement Wi Eigi Sani 'our own thing' partially called into question this consensus and although attempts to give Sranantongo official status failed, it raised a new awareness about Creole culture and Sranantongo (Gleason Carew 1982). "Creoles today consider Sranan[tongo] an integral part of their culture [...] they [like other Surinamese] continue to use Sranan[tongo], particularly for joking and expressing strong emotions" (St-Hilaire 2001: 1012). East Indians, by contrast, appear to have a high rate of 'ethnic language' retention even though competence in Dutch - at the expense of Sarnámi-and use of Sranantongo among young people has been on the rise since the 1950s. The high rate of language retention is possibly due to low rates of intermarriage and the importance of ethnically-based networks. While ethnicity is commonly invoked in Surinamese social discourses, other factors such as education and place of residence play at least an equally important role in determining language use patterns. Notwithstanding individual patterns of variation, residents of Paramaribo tend to have greater exposure to Dutch and thus often also use it in a wider range of settings while those living in rural areas tend to make greater use of languages other than Dutch.

Despite somewhat entrenched dominant views about language, the Surinamese linguistic landscape is by no means static. Urbanisation and expansion of the infrastructure and education system have brought new languages to the urban areas and have considerably increased the presence of hitherto underrepresented languages. Expansion of the local infrastructure and education system are also slowly improving access to Dutch in rural areas. Social and economic change is affecting both the social distribution and attitudes to languages. Sranantongo and other formerly denigrated languages are more widely used in the public domain (e.g. advertising, radio) and Dutch and Sranantongo are making inroads into the home and local community setting. However, we lack precise information on these issues because Suriname's contemporary linguistic context has not received much attention (but see St-Hilaire 1999, 2001). To date, research has mostly focused on the emergence and early development of the country's Afro-Surinamese languages such as Sranantongo and the Maroon languages Ndyuka, Pamaka and Saamaka (e.g. Arends 1989; Bruyn 1995; Lefebvre and Loranger 2008; Goury 2003; Migge 2003; Winford and Migge 
2007; Migge and Winford 2009; Smith 2001; Van den Berg 2007) and on documenting individual languages (Carlin 2004; Huttar and Huttar 1994). Both lines of research focus on monolingual and intra-community linguistic practices. In contrast, cross-societal communication and multilingual practices tend to receive little detailed attention (but see Migge 2007).

This chapter aims to take a first step towards improving our understanding of Suriname's contemporary linguistic context. It is based on the results of a recent sociolinguistic survey carried out among primary school children in Suriname. Exploring children's statements about their own and their families' language practices, their language attitudes, their language learning desires and self-assessment of their linguistic competence, we describe the contemporary sociolinguistic situation of Suriname and identify pertinent issues for further research. Our study echoes previous research in so far as the majority of school children present themselves as multilingual. They state using the official language, Dutch, and one or more languages in a variety of interactional dyads. While Dutch is the only officially promoted language in the country, few children display openly negative attitudes towards other languages. In fact, many desire to learn and take pride in the use of both international and local languages. However, language use patterns and alignment with the different languages, including Dutch, continue to be stratified according to ethnicity, class, residency and gender.

In this chapter we consider two types of mobility, geographic and sociocultural mobility. In our case, geographic mobility deals with urban-rural movements and movements into and out of Suriname, that is, intra-regional (within the Guiana region) and inter-regional or international (specifically involving countries from outside of the Guiana region) migration that may involve crossing of political borders. In relation to socio-cultural mobility we consider upward social mobility and social change in general. These different forms of mobility (geographical, social, cultural) are interrelated and are closely intertwined with micro- and macro-linguistic and sociolinguistic processes of change. Traditionally, geographic mobility leads to greater multilingual / plurilingual and pluricultural capitals (see the introduction to this volume). Thus (socio)linguistic change is driven by geographical and socio-cultural mobility, but at the same time it also plays an instrumental role in driving socio-cultural change which in turn tends to be linked to geographical mobility and change. The multilingual reality of present-day Suriname is the result of past processes of mobility and ongoing forms of mobility.

This chapter is organised into eight sections. We first present the sociolinguistic survey in Section 2. In Section 3 we discuss schoolchildren's languagenaming practices, showing that in the case of some languages there is a 
mismatch between official and auto-denominations that provides important insights into local language ideologies. In Section 4, we explore children's linguistic repertoires demonstrating that multilingualism is the norm and that all languages have a variety of user communities. Examining their regional distribution in Section 5 and their functional load in Section 6, we show that while language use patterns are stratified according to factors such as region of residency, social domain and gender, the distribution of languages is not fixed and is subject to variation and change. In Section 7, we explore language ideologies and their impact on language learning and maintenance. We show that while Dutch has high overt social prestige, people in Suriname also value both local and international languages. However, views about local languages are subject to quite a bit of variation, both with respect to how they are evaluated by their speakers and others. Section 8 focuses on language practices showing that multilingual practices are sharply on the rise because they are positively identified with urbanity and modern ways of life. The final section summarises the findings and discusses their implications.

Although we already had a fairly good idea about the languages currently spoken in Suriname when we began to work on issues of language and mobility in the region, we lacked precise knowledge about language use patterns in contemporary Suriname. ${ }^{2}$ There were little or no data on the following types of questions: When and for what purposes are the various languages commonly used; how are they learned; how do people evaluate them; how do people use them and are they transmitted intergenerationally; how do inter-regional dynamics and social mobility impact on patterns of language use and views about these languages?

2 The survey on the Surinamese linguistic situation (Léglise and Migge 2008-2010) is a subproject of the grant DC2M entitled The dynamics of migration and cross-border mobility between French Guiana, Suriname, Brazil and Haiti; it was funded by the french national research agency (ANR) and by the inter-establishment agency for research for development (AIRD) and hosted at the Lim A Po Institute. We would like to thank Dr. Robby Morroy (IOL) and the Lim A Po Institute for helping us to get the project off the ground, and especially Astra Deneus, but also Silvy M. for their invaluable help with the data collection and Simon B. Sana with some of the on-the-ground logistics over the two years. Special thanks are also due to Dr. Duna Troiani (research assistant (ITA) at CNRS SeDyL) who meticulously entered the majority of the interviews into excel. 
The language survey applied the same methodology that one of the authors has been using for the last ten years in her research on the language situation of French Guiana (see Léglise 2007) in order to allow for cross-regional comparison. ${ }^{3}$ The aim of this methodology is to understand language use patterns - or in Fishman's (1964) terms, Who speaks which language to whom, when, and why. It involves triangulation of three types of data: elicitation of statements on linguistic practices from school children using a language survey, observation and recording of linguistic practices in various social domains, and elicitation of local discourses on language using semi-guided interviews with a range of social actors. The former data are analyzed using mostly quantitative methods while the latter two types of data are subject to qualitative treatments focusing on the analysis of actual language use patterns and language attitudes and ideologies, respectively. In this paper, we mostly analyze the data from the school language survey, but we also draw on the latter types of data at various points. ${ }^{4}$

The language survey in Suriname was carried out between 2008 and 2010 among school children. It involved ten-minute interviews with about 3,000 upper primary school children (grades 5 and 6) in a number of rural and urban locations in the country, see Map 1. We set out to collect data in all primary schools around the country, but due to financial, logistical and time constraints we did not manage to collect data on the upper Suriname, upper Saramacca and upper Marowijne river for the time being. ${ }^{5}$ The children were mostly interviewed in Dutch by an Afro-Surinamese woman in her late 20s. In some locations interviews were also carried out by a woman in her 20 s who is of Hindoestaans (Indo-Surinamese) descent and by one of the authors of this chapter. It would have been preferable if only one interviewer had conducted all the interviews, but logistical issues made this impossible. We did not notice any differences in terms of children's responses across the three interviewers. ${ }^{6}$

3 The research project MULTI-L-GUY (Léglise 2000-2013) was funded by the French Ministry for Culture (DGLFLF), and French national research institutions: Centre national de la recherche scientifique (CNRS) and Institut de recherche pour le développement (IRD) through the research unit Structure et Dynamique des Langues and Centre d'Etudes des Langues Indigènes d'Amérique (UMR 8202 SEDYL-CELIA).

4 Collection of the latter types of data is still ongoing.

5 We intend to collect data in these locations in due course though. However, we feel confident that we have so far managed to access a representative set of locations in Suriname (e.g. smaller and larger towns and villages around the country).

6 The language label Hindi was more widely recorded by the interviewer of Hindoestaans origin than by the other interviewers suggesting the possibility that children speaking 
The children were asked to talk about their language background, their language practices, their language attitudes and language competences. The survey included the following types of questions:

- Which language(s) did you speak before starting school [if you speak several languages, in which language(s) did you learn to speak]:

- Which other language (s) didyou learn (e.g. from grandparents, school, people in the neighbourhood):

- Which language(s) do you use when speaking to

a) your mother: b) your father: c) your brother(s) and sister(s):

d) your friends: e) your mother's parents /your father's parents:

- Language $X$, do you speak it well, very well, a little?

- Which language do you use most often when you are Not at school?

- Which language(s) didyour mother/father speak when s/he was a child? (your mother's(father's birthplace):

The aim of these guided interviews was to access on a large scale the (declared) language practices and ideologies of the country's youth who make up a significant proportion of the society —an estimated $29 \%$ of the population is under the age of fifteen.

Carrying out the survey in the school setting clearly has some drawbacks. By focusing only on children who attend formal education, the survey automatically also only selects children who have knowledge of the official language, Dutch, and who also use it. However, since school enrolment among primary school children is higher than $90 \%$ (UNICEF), we submit that this way of accessing interviewees does not unduly skew the sample. Carrying out the survey in the official medium of education also inadvertently runs the risk of giving undue additional importance to this language to the detriment of other languages. We tried to minimise this issue by explaining to children that we are interested in hearing about ALL the languages that they speak and that our aim is not to test children's competence in the official language, a common misconception. ${ }^{7}$ While children who found it difficult to express themselves

Hindoestaans/Sarnámi might have accommodated to that interviewer's assumed ethnicity. However, she also focused on schools/areas where Hindoestaans/Sarnámi speakers were prevelant.

7 Prior to carrying out the survey, the main fieldworker gave a short presentation to the whole class explaining the purpose and nature of the survey. In her presentation she purposely mentioned different languages spoken in Suriname, and especially those known to be spoken in the area in question in order to give children license to talk about them. The discussion 


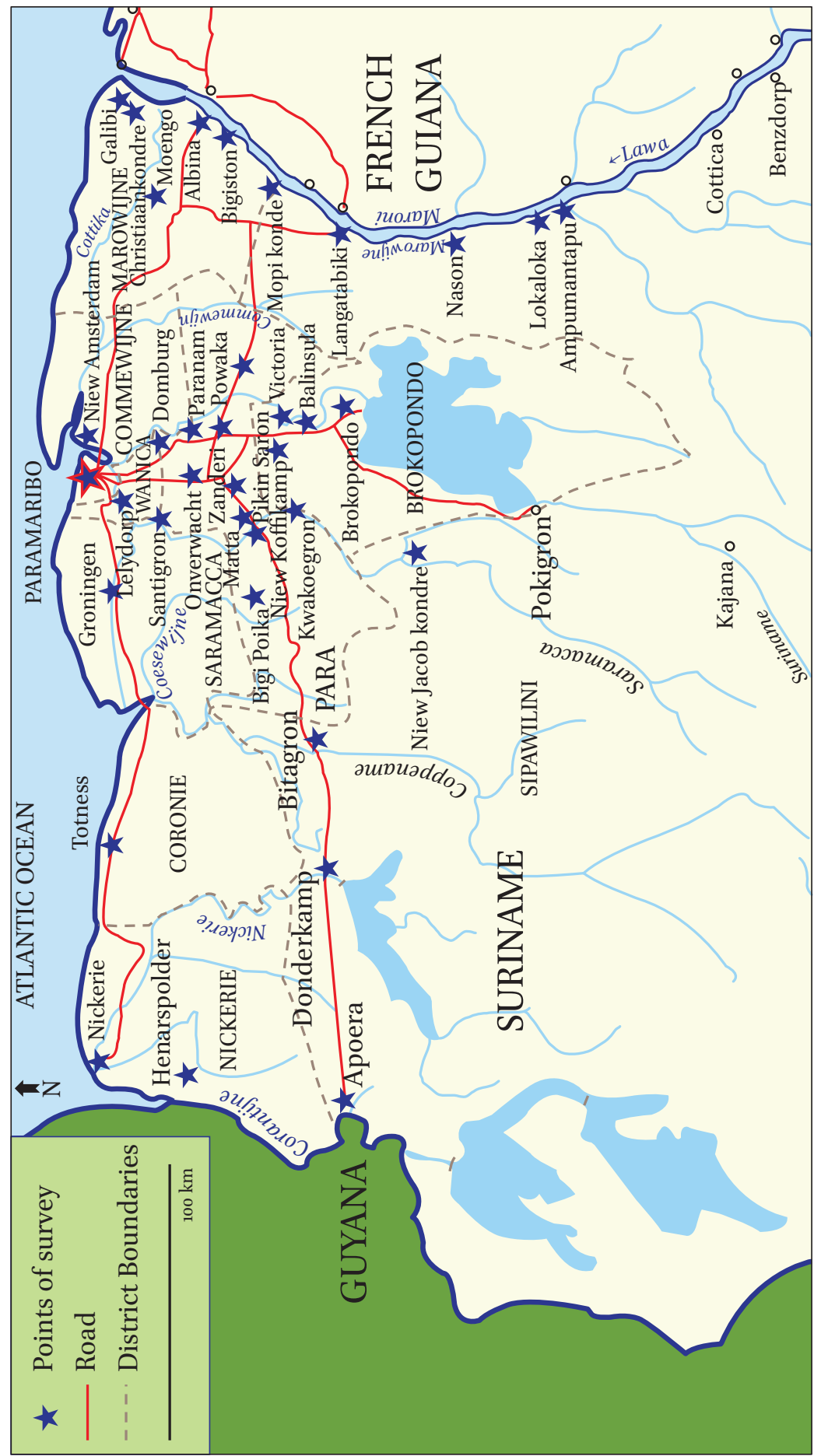

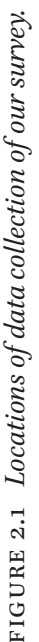


in Dutch were given the opportunity to use other languages (most typically Sranantongo), we did not think that it would have been socially appropriate to carry out the survey in another language such as Sranantongo. It is locally accepted practice to do this 'kind of work' using Dutch, especially since the school is a prime domain for its practice, and because a systematic change in this practice would have created other kinds of asymmetrical relationships between locally used languages. Nevertheless we are aware that due to carrying out the survey in the school context, children are likely to echo to a greater extent the school's views about language.

\section{Language Names and Naming Practices}

An interesting finding of the school survey was that in the case of some languages children used two or more different names to refer to them. This issue is rarely discussed in other works as it is common practice to employ the officially promoted names in the scholarly literature. Children overwhelmingly used Dutch-based names to designate European languages. Thus, Nederlands was used to designate Dutch, Frans to refer to French and Engels to talk about English. In the case of other languages, there was variation between Dutch terms and terms used among speakers of the language (sometimes called selfnaming, ethnonyms or auto-denomination in the literature). For instance, one of the Amerindian languages was sometimes referred to by the Dutch term Caraïs and at other times by its ethnonym, Kari'na. The Maroon languages that have distinct Dutch names and ethnonyms were typically designated using the former, e.g., Paramaccaans instead of Pamaka, and the language associated with Surinamese people of Indian descent was usually called by its Dutch name: Hindoestaans, Hindustaani or Hindi. Table 2.1 shows that the officially promoted term, Sarnámi (Marhé 1983), was only used in a minority of cases (5) and that the term Hindoestaans was most commonly employed among the children in the survey.

focused on using the local indigeneous terms known to us rather than official names or even alternated between official and locally used ones in order to avoid biasing usage of certain terms. Interestingly, children typically did not follow those choices in their responses, using Dutch-based names in the majority of the cases, see Section 3. 
TABLE 2.1 Names used by children to refer to the language officially called Sarnámi

\begin{tabular}{lrcr}
\hline Name & $\mathbf{L 1}^{8}$ & L2 & L3 \\
\hline Hindi & 13 & 63 & 13 \\
Hindoestaans & 91 & 134 & 37 \\
Hindoestani & 0 & 0 & 1 \\
Sarnámi & 4 & 0 & 1 \\
\hline
\end{tabular}

Children also alternated between Dutch-based language names and Dutchbased country and/or nationality names. For example, Brazilian Portuguese was referred to as Portugees, but also as Braziliaans and Brazil. ${ }^{9}$ In the case of the Maroon languages, there was some alternation between Dutch-based language terms such as Saramaccaans and Dutch-based terms that refer to their speakers, namely Saramaccaner, though the former clearly emerged as more important (Table 2.2). In some cases, the language-referring suffix -s was added to the latter form producing Saramaccaners (lit. 'the language of the Saamaka') or Aukaners.

Only in the case of two Maroon languages, Kwinti and Matawai, did children always cite the ethnonym, probably because a separate Dutch term does not exist (Kwinti) or is not very common (Matawai) - the term Matuariër was only used twice. This suggests that in the minds of children - and people in general-languages and their speakers and/or their presumed countries of origin are closely connected. This also highlights the fact that children's statements about language are influenced to varying degrees by their views about their speakers and/or their country of origin.

8 L1, L2, L3: Language cited as first language (L1), as second language (L2), ... The total amount of figures treated statistically is 1555 , involving 1555 declared Lis (sometimes several Lis are declared by the same pupil), 1530 L2s and 989 L3s. See section 4 for more details on L1, L2, L3.

9 This is probably the Dutch rendition of the Sranantongo name for Brazilian Portuguese, brasyon. 
TABLE 2.2 Names used by children to refer to the Maroon languages according to whether it was claimed as $L 1$ or as a $L_{3}{ }^{10}$

\begin{tabular}{lrr}
\hline Name & L1 & L3 \\
\hline Aukaans & 155 & 47 \\
Aukaners & 7 & 0 \\
Dyuka & 1 & 2 \\
Aukan & 1 & 0 \\
Aukaner & 1 & 0 \\
& & \\
Paramacaans & 44 & 10 \\
& & \\
Saramaccaans & 65 & 19 \\
Saramaccaners & 0 & 1 \\
Saramaka & 1 & 0
\end{tabular}

Some of the naming practices also provided insights into the relationship between languages in Suriname. The naming conventions for less widely spoken Maroon languages are a case in point. Although the members of the various Maroon groups traditionally use distinct terms to designate the different languages and value their separate identities, we found many cases where the Dutch-based names commonly used to refer to the two most widely spoken Maroon languages, Aukaans and Saramacaans, were also employed to designate the less widely spoken Maroon languages such as Kwinti, Pamaka, Aluku and Matawai respectively.11 This practice was common in coastal and urbanised areas. In the traditional villages, people used the Dutch-based ethnic names. For example, speakers of Kwinti and Pamaka initially presented themselves as speakers of Aukaans and only later explained that they are in fact speakers of Kwinti or Paramaccaans (see Section 7 for further discussion). A related practice was found in relation to Amerindian languages where children overwhelmingly made use of Dutch cover terms such as Inheemse taal

10 The spellings presented here are consistent with the ones used by our Surinamese field assistants who had been instructed to note down names in the manner in which they were presented by the children.

11 Aluku is also sometimes referred to as Boni in the earlier literature or in writings on French Guiana. 
'Indigenous language', Indiaan/Indiaanse taal 'Amerindian language' and only invoked locally used names such as Kari'na, Arawak, or Arowak, Trio, Waraos upon further questioning. Finally, the commonly used ethnonym Ndyuka was rarely (3) cited in place of the Dutch-based name Aukaans. When it was used, it was employed to designate the varieties spoken by rural populations (upriver village dwellers of the Tapanahoni River or the Sara Creek) rather than those of coastal or urbanised populations suggesting that these practices are perhaps no longer considered mainstream. This functional differentiation of the terms Ndyuka and Aukaans is possibly indicative of ongoing processes of social change that are taking place within Maroon communities (see Léglise and Migge 2006 about French Guiana). ${ }^{12}$

Reference to Suriname's lingua franca was most versatile. Children cited names like Sranantongo, or simply Sranan, its Dutch equivalent, Surinaams, its Sranantongo name, i.e. Nengre, or older terms like Negerengels and the less frequently used name Neger $(s) .{ }^{13}$ Table 2.3 shows that the name Sranantongo and its abbreviated form, Sranan, are most widely used among children. It is interesting to note that the current Dutch-based term, Surinaams, was employed much less frequently than Sranan(tongo) despite the fact that children were interviewed in Dutch. This might be indicative of the fact that the term Sranan(tongo) has been successfully mainstreamed. The low figures for the pejorative term Negerengels could suggest that it is going out of use and possibly that overall attitudes towards the language are improving. In this regard, note also that it is also mostly used by people who claim Sranantongo as an additional language rather than by L1 speakers. It is equally of interest to note

12 Thoden van Velzen and Hoogbergen (2011: 6) tell us that Okanisi (or Aukaner/Aukaner) derives from the name of the Auka plantation from where in 1757 and 1760 peace-making missions of the Dutch set out to negotiate with the Maroons that at the time resided on the Ndyuka Creek and on the Tapanahoni River. The Auka plantation was located on the Suriname River in central Suriname about go kilometres from Paramaribo. These runaways were initially referred to as 'the free blacks from Agter Auka' and later on people used the term Aukaners to designate them. They eventually came to refer to themselves as Okanisi. The name Ndyuka also existed at the time but was mostly used to refer to a subset of the people who had come to settle in the area of the Ndyuka Creek at the foot of what is nowadays called the Lely Mountains. The Okanisi refer to this region by the name of Mama Ndyuka. Both names, Ndyuka and Okanisi, are still used today. For a while the term Ndyuka was disliked because it was used as an insult in the form of 'Djoeka' among urban dwellers in Suriname. In Suriname and French Guiana the name Ndyuka is commonly used among the members of that community.

13 This term appears to be a Dutch rendition of the Sranantongo/Eastern Maroon term for Sranantongo, namely nengre and nenge $(e)$ respectively. 
TABLE 2.3 Names for Sranantongo according to whether it was declared as $L_{1}, L_{2}$ or $L_{3}$

\begin{tabular}{|c|c|c|c|c|c|c|}
\hline & L1 & & L2 & & $\mathrm{L}_{3}$ & \\
\hline Sranantongo & 49 & $55 \%$ & 141 & $30 \%$ & 344 & $58 \%$ \\
\hline Sranan & 12 & $13 \%$ & 178 & $38 \%$ & 137 & $23 \%$ \\
\hline Surinaams & 15 & $17 \%$ & 95 & $20 \%$ & 71 & $12 \%$ \\
\hline Negerengels & 13 & $15 \%$ & 48 & $10 \%$ & 32 & $5 \%$ \\
\hline Negers & & & 1 & o\% & 3 & $0 \%$ \\
\hline Nengre & & & 1 & o\% & 3 & o\% \\
\hline Neger & & & 2 & o\% & & \\
\hline Takitaki & & & & & 1 & o\% \\
\hline Total & 89 & & 466 & & 591 & \\
\hline
\end{tabular}

that another older pejorative term, Takitaki, which is currently widely used in neighbouring French Guiana to refer to Sranantongo and/or Maroon language (see Léglise and Migge 2006; Migge and Léglise 2013) was only used once during the Surinamese language survey.

In the remainder of this paper we use the language names most commonly used by the children in the survey to refer to the different languages without, however, suggesting that these names or the spelling used are the only, most widely accepted names or politically the best option.

\section{$4 \quad$ Languages in the Repertoires}

Despite the fact that Dutch is the only language that is officially promoted, the Surinamese children who participated in the language survey overwhelmingly presented themselves as multilingual (or plurilingual). $65 \%$ of the children interviewed said that they speak at least three languages, $15 \%$ claimed four or more languages and only $1 \%$ of the children said that they speak only one language. ${ }^{14}$ This suggests that multilingualism is not only a characteristic of the country, but also extends to the members of its population, who can be described as plurilingual. Following recent definitions proposed by the

14 Note that this is based on children's self-reports and does not make any claims about levels of competence. 
Council of Europe, "[p]lurilingualism differs from multilingualism, which is the knowledge of a number of languages, or the co-existence of different languages in a given society $[\ldots]$ the plurilingual approach emphasises the fact that as an individual person's experience of language in its cultural contexts expands, from the language of the home to that of society at large and then to the languages of other peoples (whether learnt at school or college, or by direct experience), he or she does not keep these languages and cultures in strictly separated mental compartments, but rather builds up a communicative competence to which all knowledge and experience of language contributes and in which languages interrelate and interact." (Council of Europe 2001: 4)

We use the term 'linguistic repertoire' (Gumperz 1982) to refer to the totality of linguistic practices, including different languages or language varieties, acquired by children. For practical reasons, we refer to them as L1, L2, L3 (and even L4 and L5) depending on when and how children learned them. L1s - children had the choice to state more than one L1-are usually acquired at home or during children's primary socialisation. Children tend to cite languages learned later in life (e.g. at school, in the playground) or lesser-used languages in the home or community environment after first-learned languages or frequently used languages. They appear here as L2 or L3 (and sometimes $\mathrm{L}_{4}, \mathrm{~L}_{5}$ ) depending on the interviewee's chosen order. For example, it might be one of the languages that are used in the home or local environment but to a lesser degree. Obviously, order of importance and frequency of use are subject to change and are not always easy to identify making it sometimes difficult to neatly rank the status of languages in a person's repertoire. For a discussion of these static categories, see Léglise (2013: 47-50). Although we use L1 / L2 / L3 for practical reasons, it is important to keep in mind that children do not have a "collection of distinct and separate competences to communicate depending on the languages [they] know, but rather a plurilingual and pluricultural competence encompassing the full range of the languages available" to them (Council of Europe 2001: 168).

Figure 2.2 demonstrates that alignment with Dutch (Nederlands) is strong among Surinamese pupils. 99\% of the school children we interviewed stated that it is in their repertoire. This is, of course, unsurprising because the survey took place in schools, the main context in which Dutch is practiced and promoted throughout the country. All the children are taught through the medium of Dutch and are thus highly likely to declare it as being part of their linguistic repertoire. However, surprisingly $63 \%$ of the children stated that Dutch is their first language. In the light of the previous literature and observations on the ground this percentage appears to be rather high and may be the effect of 
Suriname

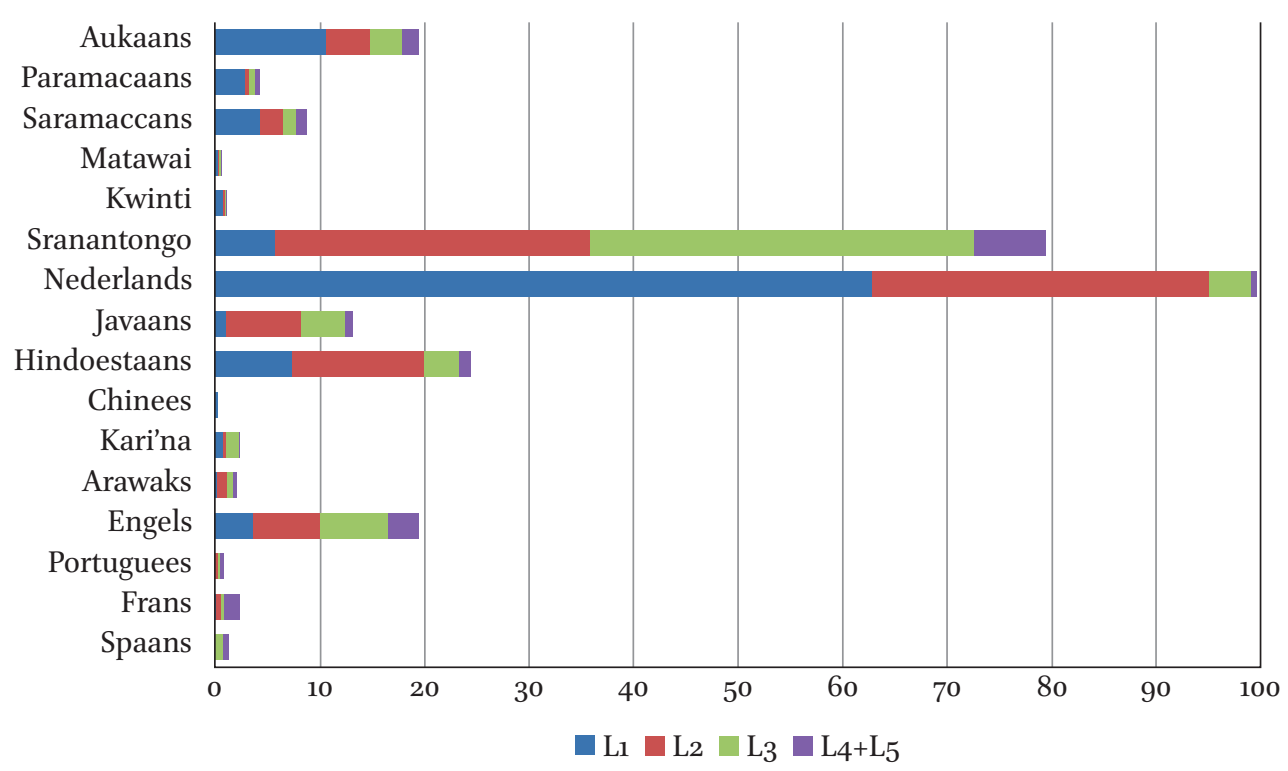

FIGURE 2.2 Languages declared in the children repertoires.

over-reporting conditioned by the context in which the survey was carried out (see Section 7 for further discussion).

Sranantongo was the second most frequently cited language in the survey, with $79 \%$ of children saying that it is part of their repertoire. In contrast to Nederlands, however, it is overwhelmingly cited as an additional language (L2, L3 or even L4). Only about $6 \%$ of children nationally claim it as a first language. These figures are in line with trends identified in previous statistics (e.g. Bruijne and Schalkwijk 1994 and national census data (A.B.S. 1967) cited in St-Hilaire 1999: 220-221) that showed that the use of Sranantongo as the principal home language has been declining since WWII. ${ }^{15}$ It confirms that Sranantongo is nowadays predominantly a linking language rather than the language of a particular ethnic group (Essed 1983) — descendants of Africans who did not flee slavery and who mostly reside in and around Paramaribo and on the coastal strip. All the other languages are cited much less frequently, but there are important differences from one language to another.

15 These surveys only investigated language among other matters and generally only asked about the principal home language rather than investigated people's linguistic repertoires and are thus much less detailed than the present survey. 
Another result of the survey was that all languages appear to have a variety of user communities. Children claim them as their main or first language (L1), as a lingua franca or as a language for special purposes such as for communication with elders. Maroon languages for example and especially Aukaans, Paramaccaans and Saramaccaans are frequently cited as Lis, but they also appear to function as lingua franca or as heritage languages ( $\left.\mathrm{L}_{2}-\mathrm{L}_{5}\right)$. Contrary to Charry et al. (1983), our survey demonstrates that Maroon and Amerindian languages are now also in contact with Dutch like any other language spoken in Suriname. Engels (English), Hindoestaans and Javaans for their part are most frequently reported as L2s even though Hindoestaans still appears to have a small but solid group of Li speakers among schoolchildren. Arawak and Kari'na, as well as Portuguese, Spanish and French, are rarely reported as Lis but mostly as additional languages.

Table 2.4 presents the kinds of first and second language combinations that are most commonly found in children's linguistic repertoires. It shows that the overwhelming majority of children who took part in the survey reported speaking Dutch and another language. Nearly twice the number of children who reported Dutch as their L2 (453) claimed it as their L1 (927). When compared with previous data these data confirm that the importance of Dutch continues to increase. By far the most commonly reported combination involved Dutch as L1 and Sranantongo as L2, again confirming the continued importance of these two languages in the Surinamese linguistic landscape. However, Dutch is also in contact with other languages of Suriname besides Sranantongo. Table 2.4 shows that other languages such as Hindoestaans, Maroon languages and Javanese also appear as important players in Suriname's linguistic context, both as L1s (e.g. Maroon languages) and as L2s (e.g. Hindoestaans, Javanese). L1 and L2 combinations that did not involve Dutch were comparatively rare and often involved a Maroon language and Sranantongo or two Maroon languages.

TABLE 2.4 Common Lr and L2 combinations found in children's linguistic repertoires

\begin{tabular}{llc}
\hline L1 & L2 & Total \\
\hline Nederlands & Sranantongo & 435 \\
Nederlands & Hindoestaans/Hindi & 192 \\
Nederlands & Javaans & 110 \\
Nederlands & Engels & 85 \\
Nederlands & Aukaans & 58 \\
Nederlands & Saramaccaans & 23
\end{tabular}


TABLE 2.4 (cont.)

\begin{tabular}{llc}
\hline L1 & L2 & Total \\
\hline Nederlands & Arawaks & 11 \\
Nederlands & Caraïbs & 6 \\
Nederlands & Paramaccaans & 4 \\
Nederlands & Frans & 4 \\
Nederlands & Kwinti & 3 \\
& & \\
Maroon languages & Nederlands & 254 \\
Aukaans & Nederlands & 151 \\
Saramaccaans & Nederlands & 55 \\
Paramaccaans & Nederlands & 41 \\
Kwinti & Nederland & 7 \\
Hindoestaans/Sarnámi & Nederlands & 102 \\
Sranantongo & Nederlands & 75 \\
Javaans & Nederlands & 13 \\
Caraïbs & Nederlands & 9 \\
Aukaans & & 5 \\
Saramaccaans & Saramaccaans & 5 \\
Sranantongo & Aukaans & 5 \\
Saramaccaans & Engels & \\
\hline & Sranantongo & 5 \\
\hline
\end{tabular}

The sociolinguistic survey also demonstrated that the languages of Suriname have partially different regional distributions. Being the official language of the country and the language of the state and the education system, Dutch is the only language that is cited all over the country. However, the proportion of children who claim it as an L1 or as an additional language varies from region to region. While just over $70 \%$ of children in Paramaribo (Figure 2.3) and in western Suriname (Figure 2.4) claim it as (one of) their L1s, this proportion reduces to just over $20 \%$ in the case of Brokopondo (Figure 2.5) and to just over $30 \%$ and $40 \%$ in the case of the eastern towns of Albina (Figure 2.6) and Moengo (Figure 2.7), respectively. The proportion of L2 users attains only $20 \%$ in Paramaribo and western Suriname and less than $10 \%$ of pupils claim it as an 
$\mathrm{L}_{3}$ to $\mathrm{L}_{5}$. The figures sharply contrast with those obtained for central Suriname (the district of Brokopondo, Figure 2.5) where Dutch is claimed as an L2 by $60 \%$ and as an $\mathrm{L}_{3}-\mathrm{L}_{5}$ by roughly $10 \%$ of children. The figures for coastal eastern Suriname (Figures 2.6 and 2.7) closely resemble those for central Suriname. Taken together, the figures for the regional distribution of languages suggest that Dutch has different functions throughout the country. In the capital and western Suriname, it appears to mostly function as an Li while in other parts of the country it is mainly used as a linking language.

Like Dutch, Sranantongo is also widely represented in the repertoires of children from all over the country. However, people's orientation to Sranantongo is different in two respects. First, it is claimed to a somewhat lesser degree. In the capital, in western Suriname and in the border town of Albina more than $90 \%$ of children declared using Sranantongo for some of their interactions, see Table 2.5. This figure decreases to less than $60 \%$ in the case of the Brokopondo district and to just over $70 \%$ in the case of the eastern town of Moengo. Second, Sranantongo is overwhelmingly claimed as an additional language and rarely as an Li. In Paramaribo, for instance, less than $5 \%$ of children report it as their L1, while about $70 \%$ of children claim it either as their L2 (about $46 \%$ ) or as their $\mathrm{L}_{3}-\mathrm{L} 5$. The figures for western Suriname are comparable; however, in central and eastern Suriname the number of children who claim it as an $\mathrm{L}_{3}-\mathrm{L}_{5}$ far outweighs those who say that it is their $\mathrm{L}_{1}$ or $\mathrm{L}_{2} .50 \%$ of children from Brokopondo, $60 \%$ in Moengo and $69 \%$ in Albina say that they use Sranantongo as an $\mathrm{L}_{3}-\mathrm{L}_{5}$. These figures confirm that Sranantongo functions as a lingua franca rather than as the main or community language of a specific social group in Suriname. The difference in representation of Sranantongo and Dutch in the repertoires of Surinamese children is indicative of different attitudes towards these languages and ongoing social change. We discuss this further in Section 7 .

TABLE 2.5 Percentage of children claiming to use Sranantongo for some functions in different areas of Suriname

\begin{tabular}{lrrr}
\hline Area & \multicolumn{1}{c}{ L1 } & L2 & L3-L5 \\
\hline Paramaribo & $3 \%$ & $46 \%$ & $19 \%$ \\
Western Suriname & $5 \%$ & $40 \%$ & $44 \%$ \\
Albina & $10 \%$ & $14 \%$ & $69 \%$ \\
Brokopondo & $3 \%$ & $5 \%$ & $50 \%$ \\
Moengo & $7 \%$ & $7 \%$ & $60 \%$ \\
\hline
\end{tabular}


The remaining languages are much more strongly regionally stratified. Hindoestaans is reported by children attending school in Paramaribo, the Para and Wanica regions located around the capital and in western Suriname, particularly in the district of Nickerie. It was not cited at all in the Brokopondo area and rarely in eastern Suriname. In Albina 8\% of children said that they speak Hindoestaans and in the Moengo area it was not represented at all. Hindoestaans is also predominantly claimed as an additional language. In western Suriname it was named by about $45 \%$ of children, but only just over $15 \%$ of these children said that it is their L1. The remaining children reported it as their L2 (about $17 \%$ ) or as their $\mathrm{L}_{3}-\mathrm{L}_{5}$ (about $13 \%$ ). In Paramaribo, by contrast, just under $20 \%$ of children cited Hindoestaans as being in their repertoire and of these only about $5 \%$ said that it is their $\mathrm{L} 1,3 \%$ that it is their $\mathrm{L}_{3}-\mathrm{L} 5$ and about $10 \%$ present it as their L2. Finally, in Albina all $8 \%$ of children who reported speaking Hindoestaans claimed it as an additional language, either as their L2 or L3. The other main Asian-Surinamese language in Suriname, Javanese, has a somewhat similar regional distribution as Hindoestaans, being mainly claimed by children in the Paramaribo area and in the Para, Wanica and Commewijne districts. None of the children in central and eastern Suriname made reference to Javanese. In Paramaribo, where over $30 \%$ of children said that they used it for some of their interactions, only about $1 \%$ of these children reported it as their L1. This contrasts with just over $20 \%$ of children who said that it is their $\mathrm{L} 2$ and just over $10 \%$ who claimed it as a $\mathrm{L}_{3}-\mathrm{L}_{5}$. In western Suriname, just over $10 \%$ of children who said that Javanese is in their repertoire claimed it as an additional language, as an L2 (4\%), an L3 (6\%) or an L4-L5 (1.5\%). Finally, varieties of Chinese were claimed by next to none of the children who took part in the survey. This is somewhat surprising because we know that about $2 \%$ of the population self-identify as being of Chinese background and that most of them reside in Paramaribo. At this point it is not clear whether we simply missed Chinese-speaking children or whether these children, for one reason or another, reported having languages other than Chinese in their repertoire. ${ }^{16}$ This issue requires further investigation.

In contrast with Asian-Surinamese languages, the languages of the Maroons are marginally represented in western Suriname (about $7 \%$ ), are comparatively underrepresented in the capital (about $35 \%$ across four languages), but clearly dominate in central and eastern Suriname. For instance, $50 \%$ of children in Brokopondo said that they use Aukaans and more than $80 \%$ said that they use Saramaccaans. Only about $8 \%$ declared speaking Matawai and $2 \%$ cited

16 It is possible, for instance, that we 'missed' Chinese-speaking children because they predominantly attend the Chinese school and/or other expatriate schools in the city. 
Kwinti, two of the less widely spoken Maroon languages. This contrasts with eastern Suriname where more than $65 \%$ of children in Albina and nearly $100 \%$ of children in Moengo stated that Aukaans is in their repertoire. Saramaccaans does not appear to be widely represented in eastern Suriname since only $10 \%$ of children in Albina and 8\% of pupils in Moengo reported speaking it. The other Maroon languages are not cited at all, but this does not necessarily mean that they are not used at all in these locations as some of the children who are speakers of less widely spoken Maroon languages such as Paramaccaans appeared to use the term Aukaans to refer to Paramaccaans. Children in Paramaribo reported using four Maroon languages, Aukaans (about 17\%), Matawai (about 1.5\%), Paramaccaans (about 1\%), and Saramaccaans (about $15 \%)$. The more widely spoken Maroon languages, Aukaans and Saramaccaans, appear to have large mother tongue speaker communities in eastern and central Suriname, respectively. For instance, in the district of Brokopondo, nearly $50 \%$ of children said that Saramacaans is their L1 compared with only $30 \%$ of children who reported it as an additional language, either as an L2 $(20 \%)$ or as an $\mathrm{L}_{3}-\mathrm{L}_{5}(10 \%)$. The figures for Aukaans were a bit lower than those for Saramaccaans, but still point to the existence of a sizable native speaker community. Just over $20 \%$ of children in Brokopondo said that Aukaans is their L1 and nearly $30 \%$ claimed it as an additional language, either as an L2 (5\%), and $\mathrm{L}_{3}(15 \%)$ or as an $\mathrm{L}_{4}-\mathrm{L}_{5}(8 \%)$. In eastern Suriname Saramaccaans appears to be marginally represented since few children claimed it overall and if they did, it was merely reported as an additional language $-8 \%$ of children in Moengo and $10 \%$ in Albina said that Saramaccaans is their $\mathrm{L}_{4}-\mathrm{L} 5$. This contrasts with childrens' categorisations of Aukaans. $52 \%$ of children in Moengo and about $46 \%$ in Albina reported speaking Aukaans as their main language ( $\mathrm{L1}$ ) and just over $40 \%$ in Moengo and about $15 \%$ in Albina said that they use it as an additional language.

In Paramaribo where overall speaker numbers were lower, about half of the children who reported speaking Aukaans or Saramacaans declared it as their L1. Among those who claimed them as additional languages, $4 \%$ said that they speak Aukaans as an L2 and only 1\% reported Aukaans as their L4-L5. Saramacaans was claimed as an $\mathrm{L}_{2}$ and as an $\mathrm{L}_{3}-\mathrm{L}_{5}$ by $3 \%$ of children. The numbers for the other Maroon groups are very small (less than $2 \%$ ), but in the case of both Paramaccaans and Matawai they were reported as Lis and as additional languages.

Amerindian languages were rarely mentioned by children throughout the entire country. None of the children we interviewed in Paramaribo and the towns of western Suriname said that they spoke an Amerindian language. In eastern Suriname, about $3 \%$ of children in Albina reported having Kari'na 
in their repertoire as an L4. Arawak, Kari'na and lesser-used Amerindian languages were, however, cited in rural locations in eastern Suriname (Galibi), central Suriname (Powaka, Lebi Doti) and in central western Surinamese villages such as Matta, Pikin Saron, Bigi Poika, Konomerume/Donderskamp and Christiaankondre. Although many of these villages are predominantly inhabited by people of Amerindian origin, Amerindian languages were mostly cited as additional languages $\left(\mathrm{L}_{3}-\mathrm{L} 2\right)$ rather than as L1s. This suggests that language attrition rates continue to be high in the case of Amerindian languages.

When comparing the regional distribution of languages obtained from the language survey with the distribution of (self-ascribed) ethnic categories identified by the 2004 national census (SIC213-2005/02), some interesting patterns emerge. The census data and the survey data match up closely with respect to some languages. For instance, the census data show that the proportion of people who claimed Maroon (Marron) ethnicity in the district of Nickerie (123) constitutes a negligible minority compared with the number of people claiming Hindostaan ethnicity $(21,921)$ who constitute the majority group in this district. ${ }^{17}$ The number of Javanese (Javaan) - 6,114 Javanese-is intermediate between the two groups. This is also mirrored in the results from the language survey where nearly half of all children in Nickerie reported speaking Hindoestaans, just over $10 \%$ reported speaking Javanese but less than $10 \%$ claimed a Maroon language (Figure 2.4). This suggests that there is a relatively close match between ethnicity and language identification and maintenance. However, there is some discrepancy between figures for ethnicity and language use in the case of residents of Paramaribo. In the capital, similar numbers of people claim Maroon and Javanese ethnicity-23,343 Maroons and 29,188 Javanese - which matches up with the figures from the language survey; both Javanese and Maroon languages are each claimed by about $40 \%$ of children in Paramaribo. However, a different picture emerges in the case of Hindoestaan people. While 53,952 people claimed Hindoestaan ethnicity in Paramaribothat is twice the number of people who claimed Maroon and Javanese ethnicity—less than $20 \%$ of the children in Paramaribo stated having Hindoestaans

17 According to the census, there were 33,624 people of Surinamese nationality and 36,639 people in total living in the district of Nickerie in 2004. The third and fourth largest ethnic groups were people who claimed Creole $(3,551)$ and mixed $(3,273)$ ethnicity. For most districts, the census data list figures for the following ethnic groups separately: Amerindian (Inheems), Maroon (Marron), Creole (Creool), Indo-Surinamese (Hindoestaan), Javanese (Javaan), Chinese (Chinees), Causasian (Kaukasisch), mixed (Gemengd). There are also categories such as others (Overige), 'don't know' (Weet niet) and 'no response' (Geen Antwoord). SIC226-2006-08: 27-29. 
in their repertoire. This suggests that in the case of people of Hindoestaan ethnicity in Paramaribo, ethnicity and knowledge of the ancestral language do not go hand-in-hand which is suggestive of language attrition and of changes in the definition of membership in ethnic groups. Examination of the census category 'mixed' (Gemengd) in the national census also suggests that willingness to align with a specific ethnic grouping is undergoing change in Suriname and that this change is regionally stratified. While only comparatively few people claimed the ethnic category mixed in the district of Nickerie $(3,273),{ }^{18}$ this figure rises to 39,694 people in Paramaribo. ${ }^{19}$ Further research is needed on the issue of ethnicity and its relation to language, including regional variation.

Apart from Dutch, children also stated speaking other European languages such as Engels 'English', Portugees 'Portuguese' and Frans 'French'. English was cited by children from all over the country. Figures 2.2-2.6 suggest that about $18 \%$ of children in Paramaribo, just over $30 \%$ in western Suriname, about $20 \%$ in eastern Suriname (20\% in Moengo and $18 \%$ in Albina) and about $13 \%$ of children in the Brokopondo district said that English is part of their repertoire. In all of these locations it is mainly claimed as an additional language. Only about $4 \%$ of children in Paramaribo, $2 \%$ in western Suriname and Albina and about $1 \%$ in the Brokopondo district claimed it as an L1 though. In eastern Suriname and the Brokopondo district $\mathrm{L}_{3}-\mathrm{L}_{5}$ usage outweighed $\mathrm{L} 2$ usage while in Paramaribo and western Suriname it is cited to the same extent as L2 and as $\mathrm{L}_{3}-\mathrm{L}_{5}$. English is predominantly claimed in the western town of Apoera where almost all the children reported speaking it: 18 children out of 42 claimed it as an $\mathrm{L} 1,14$ as an $\mathrm{L} 2$ and 7 as an $\mathrm{L}_{3}$.

Children only rarely reported using Portuguese. It appears as an additional language ( $\mathrm{L}_{2}$ and $\mathrm{L}_{4}$ ) in western Suriname (about 1\%), the Brokopondo district (about 3\%), and in Paramaribo (less than 1\%). Finally, while French is claimed as an additional language with a very low frequency in several locations such as western Suriname (L4: 1\%) and the Brokopondo area (L4: $2 \%$ ), its proportion rises to $10 \%$ in Moengo and $28 \%$ in the border town of Albina which is only a five minute boat ride from French Guiana. In Moengo, it is only cited as an additional language $\left(3 \% \mathrm{~L} 2,3 \% \mathrm{~L} 3,3 \% \mathrm{~L} 4-\mathrm{L}_{5}\right)$ while in Albina it was claimed by about $3 \%$ of children as an L1. A further $8 \%$ reported it as L2, 3\% as an $\mathrm{L}_{3}$ and about $13 \%$ as an L4. In Section 7 , we discuss the role of 'foreign' languages in the repertoires of children further.

\footnotetext{
18 The total Surinamese population of Nickerie was 33,624 in 2004 (SIC226-2006-08).

19 Compare this with the number of people who claim Creole (66,797), Indo-Surinamese $(53,952)$, Maroon $(23,343)$ and Javanese $(29,188)$ ethnicity in Paramaribo. SIC224-20o6-06: 29-30.
} 
Paramaribo

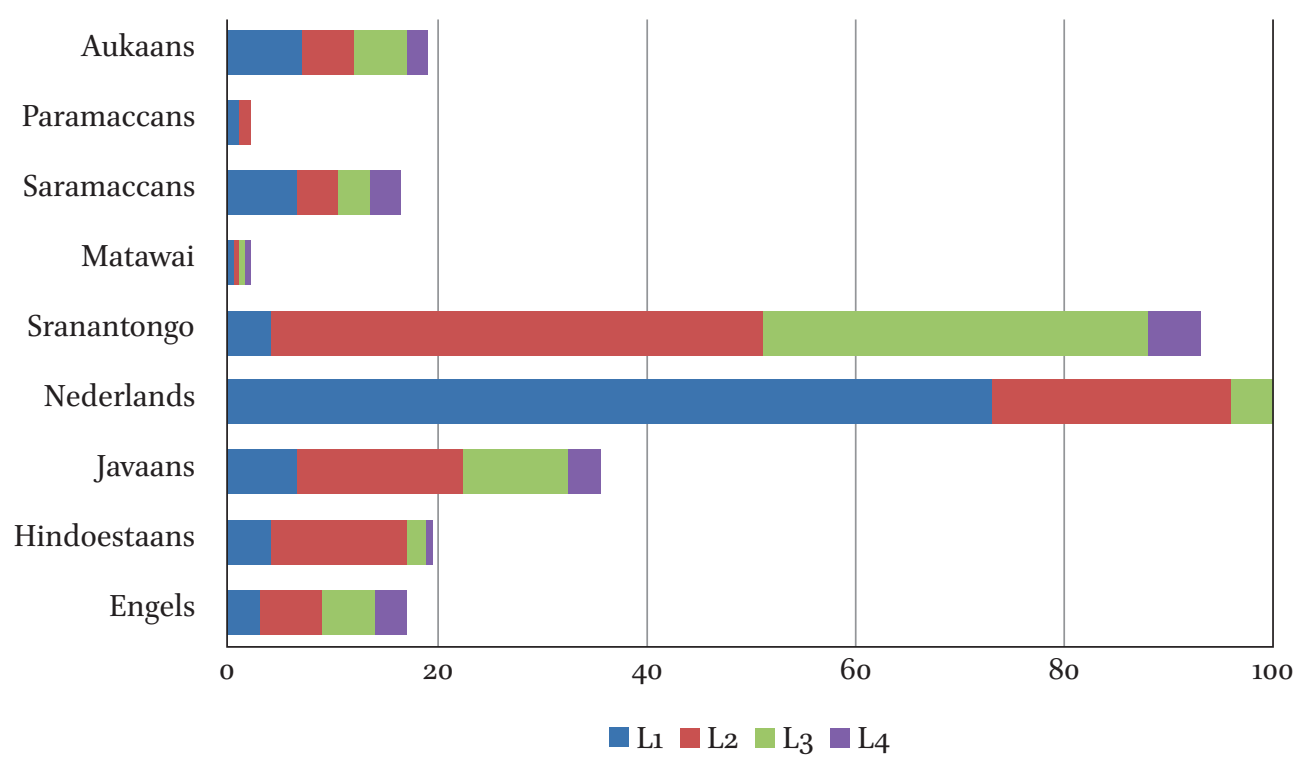

FIGURE 2.3 The distribution of languages in Paramaribo, the capital of Suriname.

Total West (Nickerie, Coronie)

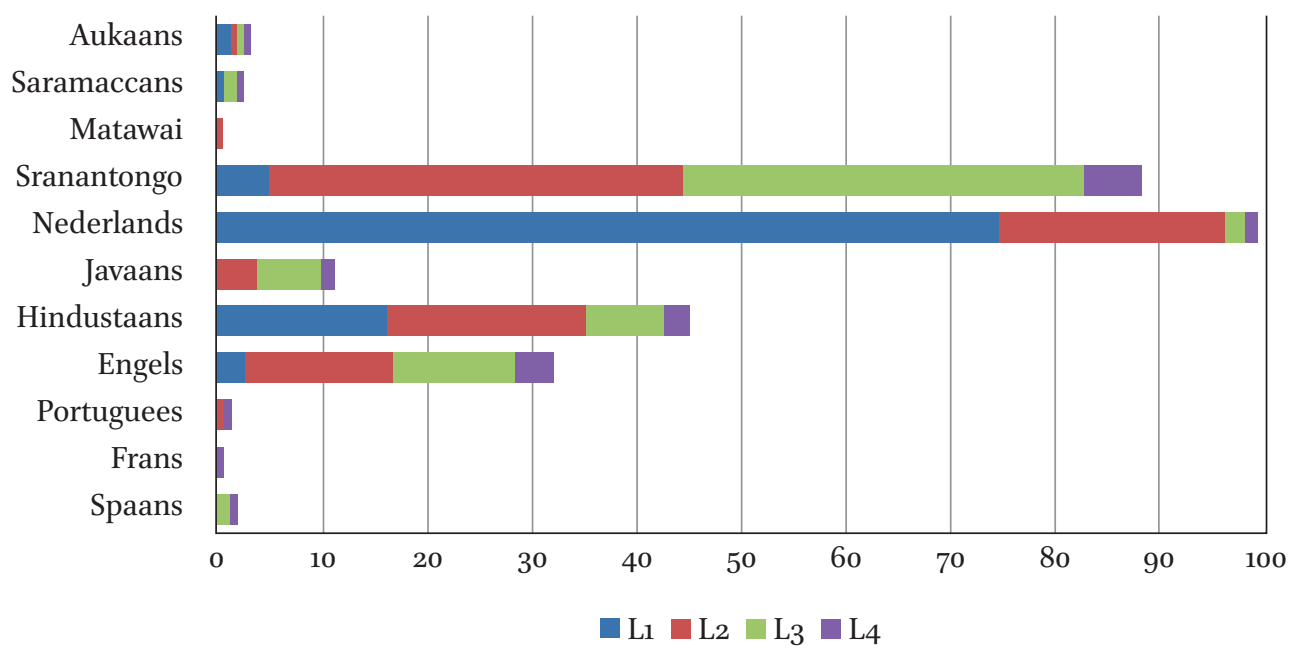

FIGURE 2.4 The distribution of languages in western Suriname (Districts of Nickerie and Coronie). 
Total Brokopondo district

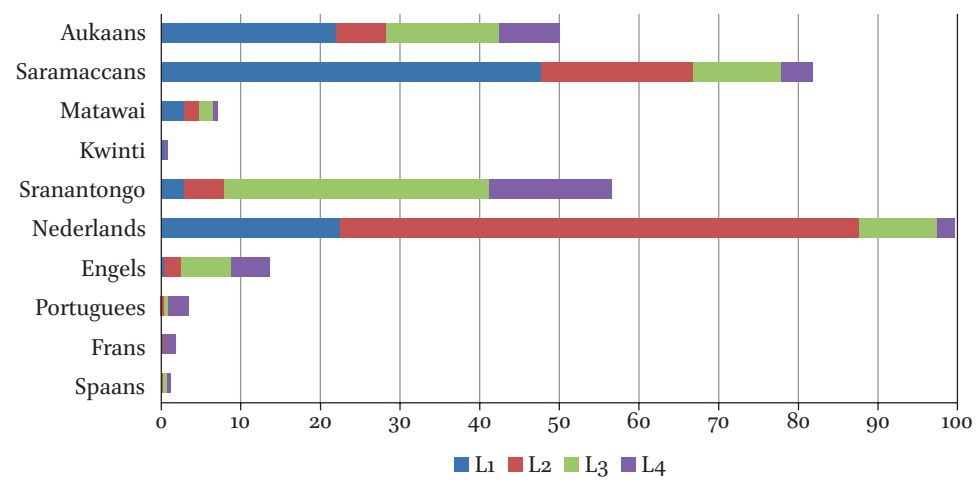

FIGURE 2.5 The distribution of languages in the Brokopondo district.

Albina

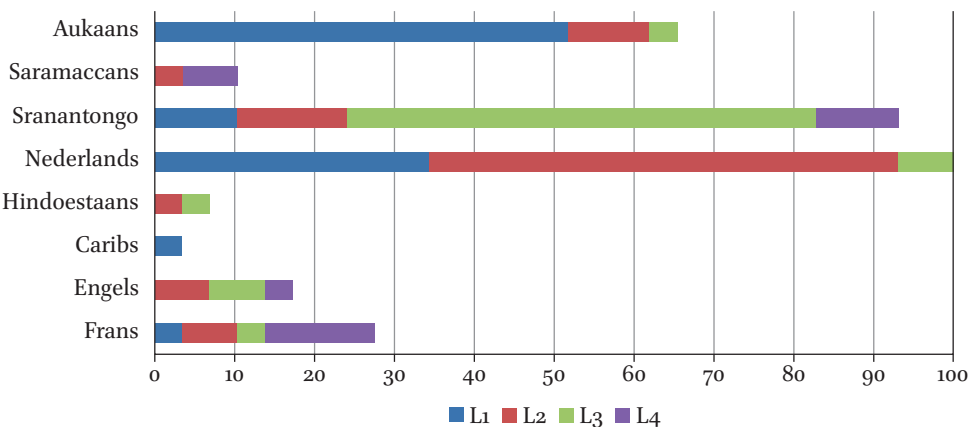

FIGURE 2.6 The distribution of languages in Albina and surrounding area in eastern Suriname.

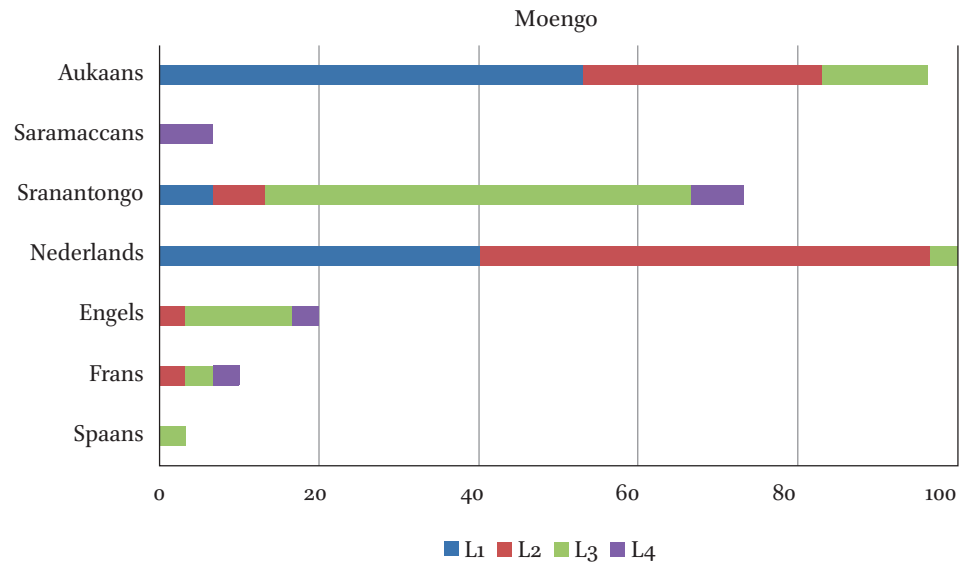

FIGURE 2.7 The distribution of languages in Moengo and surrounding areas in eastern Suriname. 
In Section 4 we showed that children all over Suriname presented themselves as bilingual or multilingual. They reported using distinct languages in different interactional dyads, but many of them also said that they use two or more languages in the same interactional dyad suggesting that interactional contexts are not always or typically identified with just one language. This suggests that the classic functional division of languages often invoked in the literature which designates certain languages such as Hindoestaans, Javaans, the Maroon Creoles as home or community languages and others, notably, Sranantongo and Dutch (Nederlands) as official and/or out-group languages (see for instance Carew 1982: 2 ) does not match up with children's perception. ${ }^{20}$ Following Fishman's (1964) idea of language use in specific domains, we noticed a considerable weakening of the classic functional loading of languages which is probably the result of social change. Our analysis revealed several patterns. The most common pattern involved the use of Dutch together with one or more 'home' language(s) in one or more interactional dyads. For instance, an eleven-year-old girl from Kwakugron in the Para region told us that she speaks Matawai, Nederlands and Aukaaners. She speaks Matawai and Aukaaners only with her mother's and father's parents respectively. However, for all other types of interactions she stated using either Matawai or Aukaaners and Nederlands as shown in the figure 2.8 below.

There are, however, also a few cases where it is Sranantongo that alternates with a so-called home language. Take, for instance, the case of a twelve-yearold boy from Commewijne (Figure 2.9). He presented himself as trilingual, saying that he speaks Surinaams (Sranantongo), Javaans, and Nederlands. He stated using Javaans and Surinaams with his mother and father, Surinaams with his siblings and friends, Javaans with his maternal grandparents and Javaans and Nederlands with his paternal grandparents. It is interesting to note that Javaans functions as a linking language within the mother's familywhereas Surinaams plays the same role with respect to the father, the father's parents, siblings and friends. Interestingly, the number of languages used in the same interactional dyad appears to be greatest in interactions with the grandparents. This and many other examples show that children may use three or more languages in the same interactional context (see also Figure 2.11 below).

20 When reporting childrens' language use, we use the language names that they used. The meta discourse mostly uses English labels to facilitate comprehension. If we were certain that two terms have the same denotation, we also indicate that by providing both names, e.g. one in brackets. 


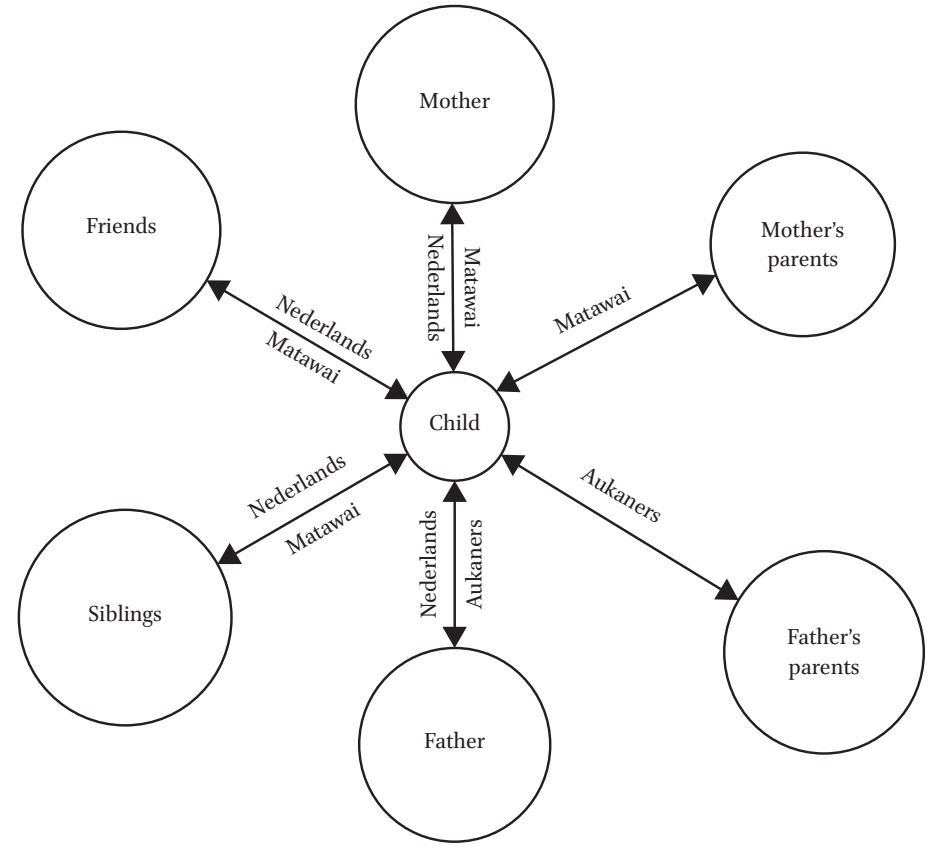

FIGURE 2.8 Languages used by a twelve-year-old girl from Kwakugron.

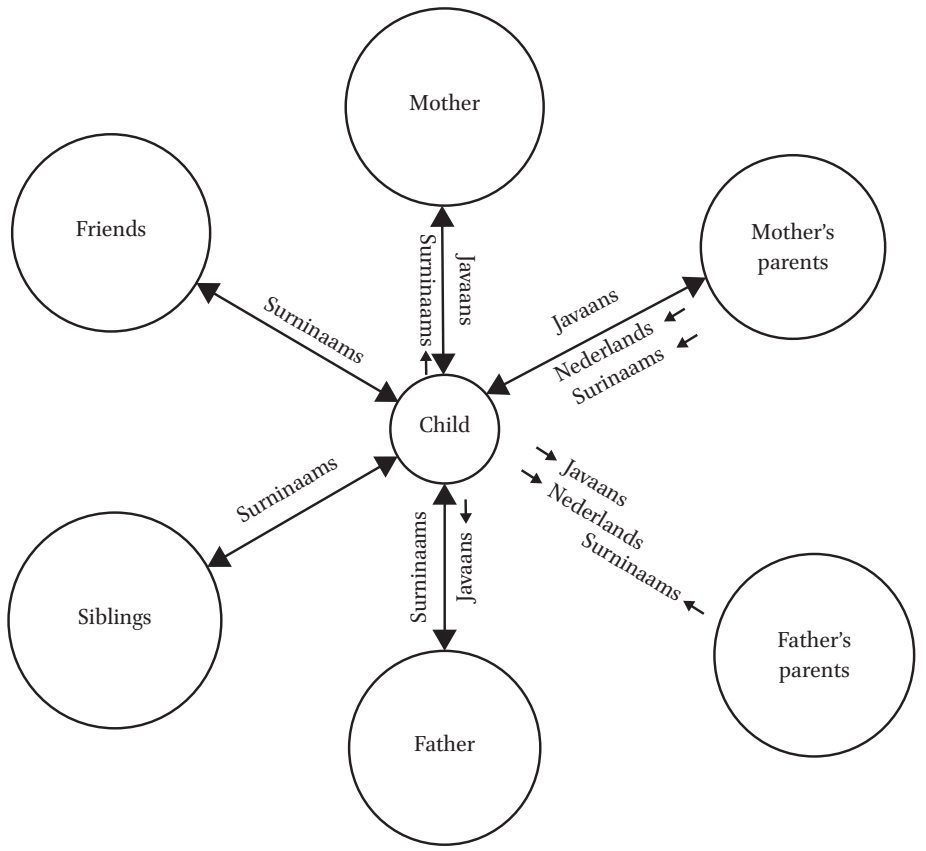

FIGURE 2.9 Languages used by an eleven-year-old boy from Commewijne. 
In research on multilingualism, especially in settings that have been undergoing social changes involving processes of urbanisation and a significant increase in school attendance rates as in the case of Suriname, it is often assumed that ancestral or minority languages are practiced and promoted in interactions with the grandparent generation while the official or national language is used in interactions with parents, peers and outsiders. Our data show that there are indeed cases in our corpus where monolingual usage of an ancestral language is associated with interactions with the grandparent generation. For example, a ten-year-old boy from Nickerie (Figure 2.10) said that he uses Nederlands with his parents, Sranantongo with his friends, but only Hindoestaans with his grandparents.

However, this classic distribution of languages does not seem to be the most common one as there are also a number of cases where it is the grandparent generation rather than the parent generation that appears to promote the use of the official language or where more than one language is also regularly used with members of the grandparent generation. In Figure 2.9, for instance, both supra-regional languages, Sranantongo and Nederlands, appear in interactions with the grandparents. Figures 2.11 and 2.12 are two examples of Nederlands-speaking grandparents. Figure 2.11 represents the language use

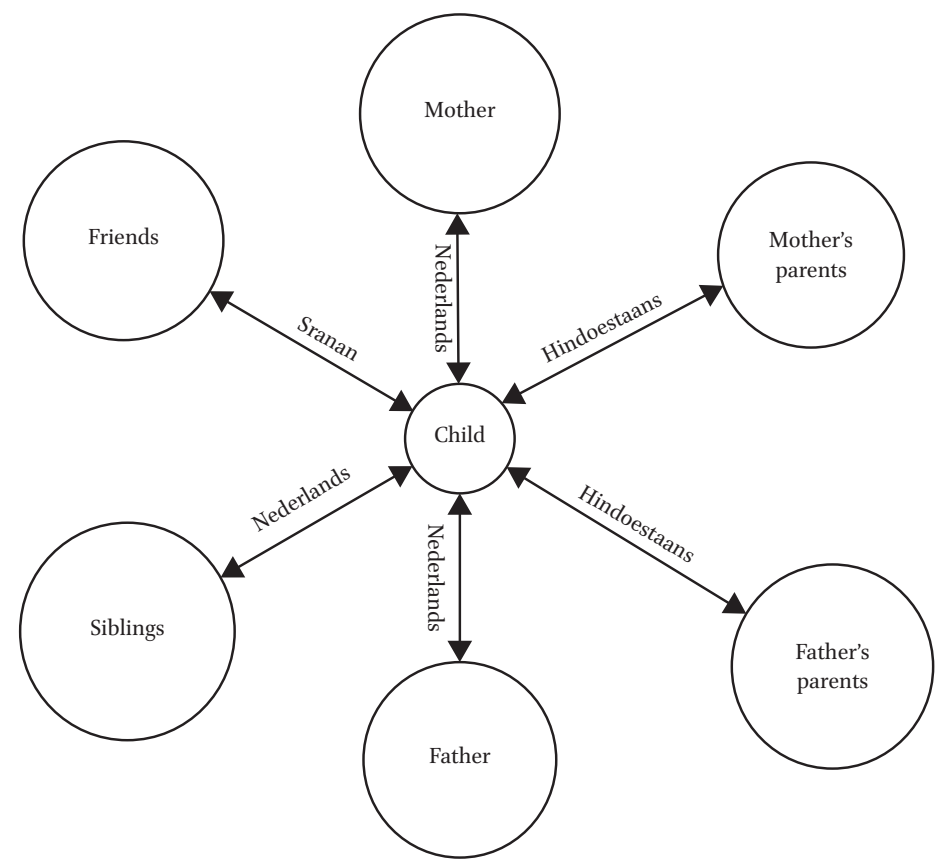

FIGURE 2.10 Languages used by a ten-year-old boy from Nickerie. 


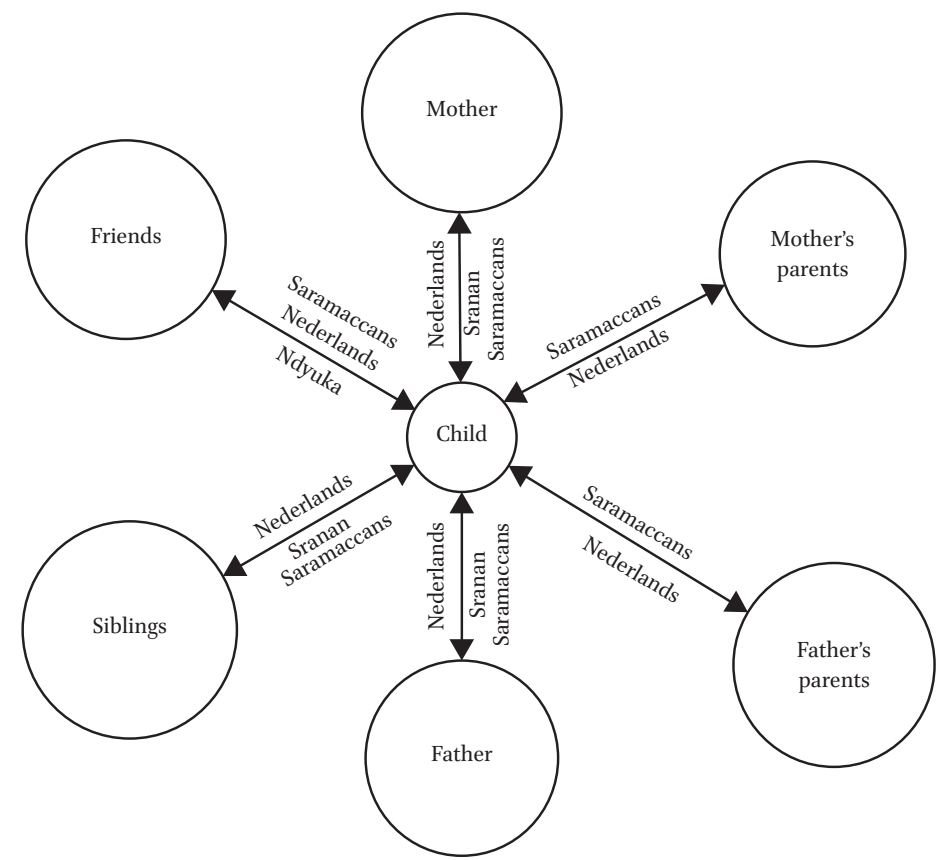

FIGURE 2.11 Languages used by a 14 year boy from the Brokopondo district.

patterns reported by a fourteen-year-old boy from the Brokopondo district. He employs Nederlands, Sranantongo and Saramaccaans with his parents and siblings, Ndyuka instead of Sranantongo with his friends (together with the other available languages in their linguistic repertoire), but only Saramaccaans and Nederlands with both his grandparents.

Figure 2.12 represents another ten-year-old child from the village of Balin in the Brokopondo district who said that she uses only Nederlands with both sets of grandparents. The latter distribution of languages is not as uncommon as one might think and might be indicative of changes in educational patterns and language ideologies in Suriname. Until the 1980s, all languages other than Dutch had low overt prestige and upward social mobility was dependent on knowledge of Dutch. Parents therefore often adopted Dutch as their family language in order to give children a 'head start in life' and in order to create an aura of modernity for themselves. In the last thirty years this has been changing somewhat. On the one hand, Dutch has become more distinctly Surinamese through influence from other languages, most notably Sranantongo, and on the other hand, languages like Sranantongo, but increasingly also Maroon languages, have become more acceptable means of communication in domains previously reserved for Dutch (Charry 1983: 151). At the same time, it is also 


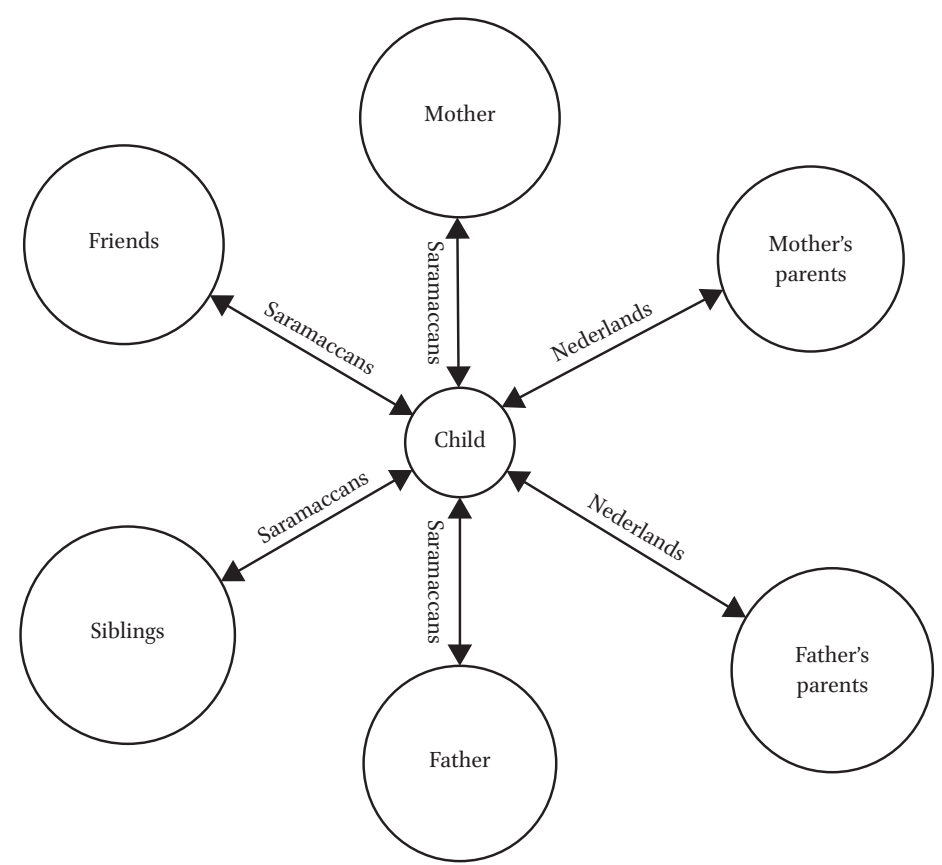

FIGURE 2.12 Languages used by a 10 year old girl from the Brokopondo district.

possible that this non-traditional distribution is the result of educational problems (problems with teacher recruitment and training, strikes etc.) that have been affecting Suriname since the civil war in the 1980s. Many of the people who grew up in rural areas between the late 1980s and 2000 had little sustained access to education. Lack of access to Dutch and negative views about townspeople have in some areas led to a revival of traditional language practices.

Language use with siblings and with friends also does not appear to follow a single pattern either. In some cases children stated using the same languages with all of their family members and with friends. In many cases, interactions with siblings and friends are distinguished from those with elders. Figure 2.9 is a good illustration of this. Another example is shown in Figure 2.13. Here a thirteen-year-old boy from Nickerie reported using Nederlands with his parents, Hindoestaans with his grandparents and only Sranantongo with his peers.

This pattern could be taken to suggest that Sranantongo is the language of peer solidarity while Nederlands and Hindoestaans are languages of authority and distance appropriate for different types of interactional dyads. However, 


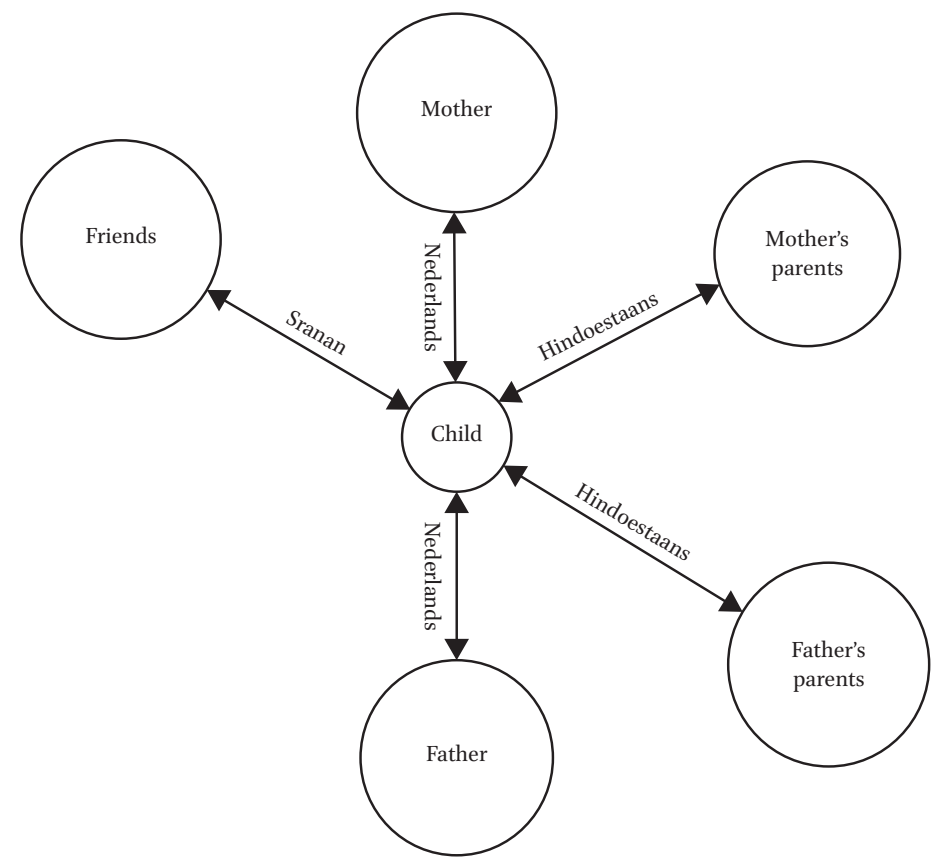

FIGURE 2.13 Languages used by a 13-year-old boy from Nickerie.

patterns of language use reported by other children challenge this functional stratification of languages (see Figures 2.9 and 2.11 as counter-examples).

The survey also revealed differences in practices between different language communities. In the case of Sarnámi/Hindoestaans it is quite obvious that its monolingual use is most typically found in interactions between children and their grandparents (see Figures 2.10 and 2.13) suggesting that the latter are either more often quasi-monolingual and/or that they function as promoters of the ancestral language (and culture). Bilingual practices tended to be linked to interactions with parents suggesting that they often take on the role of language brokers who create a link between the ethnic and the national culture. Monolingual use of either Sranantongo, in the case of boys, and Nederlands in the case of girls and boys, or use of both these languages tended to be more typical of peer group interactions, including interactions with siblings while monolingual or bilingual use of Hindoestaans with peers appears to be quite rare. These findings support Marhé (1983) who argued that young IndoSurinamese in the majority prefer to align with urban life-styles and a Sranan or national identity which is linked to Sranantongo and Dutch rather than a specific ethnic identity associated with Sarnámi/Hindoestaans. At this stage it 
is not clear whether the greater use of Sranantongo and Dutch is necessarily only indicative of language attrition or might represent a case of age grading.

Javaans is comparatively little mentioned by children throughout Suriname who participated in the survey. Analysis of the language use profiles of $135 \mathrm{chil}-$ dren who said that Javaans is part of their linguistic repertoire revealed three broad patterns. First, Javaans is predominantly practiced with grandparents and in the majority of cases (93 out of 117) it is the only language used with them. The remaining children reported using it either in conjunction with Nederlands (16) or with Sranantongo (8). Second, if Javaans is used in the childparent dyad at all, it is typically used with the mother and predominantly in conjunction with Nederlands. While only six children reported speaking only Javaans with their mother, twelve said that they use both Nederlands and Javaans in this setting. Third, Javaans is rarely used with peers and then typically with other languages such as Sranantongo or Nederlands (see Figure 2.3). These patterns of language use involving Javaans are indicative of a rupture of intergenerational language transmission, confirming St-Hilaire's (2001: 1012) assertion that "Dutch and, to a lesser extent, Sranan[tongo] exert considerable assimilative pressure on the Javanese". Javanese appears to be on its way to becoming a heritage language whose use will decrease in step with that of the oldest living generation.

Amerindian languages appear to be much more vulnerable than Javaans though. Only very few children said that an Amerindian language is part of their linguistic repertoire and usually specified that they only have so-called passive competence in it; that is, they are able to understand (some) spoken productions but their ability to speak these languages is severely reduced. Those who reported speaking an Amerindian language had usually learned it from their grandparents, particularly their grand-mother, and also only used it in this interactional dyad. A very small number of children in a few rural locations also stated using an Amerindian language such as Kari'na with their parents, but in these cases it was used in conjunction with either Dutch and/ or Sranantongo.

In contrast to Amerindian languages, language maintenance rates for Maroon languages appear to be quite high and the user communities of some Maroon languages appear to be growing. First, Table 2.6 shows that a relatively large number of the children who participated in the survey reported having a Maroon language in their linguistic repertoire and many of these children also said that it is (one of) their Lis. 
TABLE 2.6 The place of Maroon languages in children's linguistic repertoires in Suriname

\begin{tabular}{lcccccc}
\hline Reported as: & Aukaans & Paramaccaans & Saramaccaans & Matawai & Kwinti & Sranantongo \\
\hline L1 & $11 \%$ & $3 \%$ & $4 \%$ & $0.2 \%$ & $0.6 \%$ & $6 \%$ \\
L2 & $4 \%$ & $0.5 \%$ & $2 \%$ & $0.2 \%$ & $0.3 \%$ & $30 \%$ \\
L3 & $3 \%$ & $0.6 \%$ & $1.5 \%$ & $0.1 \%$ & $0.06 \%$ & $37 \%$ \\
L4 and L5 & $2 \%$ & $0.5 \%$ & $1 \%$ & $0.06 \%$ & $0.06 \%$ & $7 \%$ \\
in the repertoire & $19.5 \%$ & $4.5 \%$ & $9 \%$ & $0.6 \%$ & $1 \%$ & $79.5 \%$ \\
& \multicolumn{2}{c}{$24 \%$} & & & & \\
\hline
\end{tabular}

Second, children stated using them in a wide range of interactional contexts such as with parents, elders, peers and siblings. Third, in both family and peer interactions they are frequently cited as the only medium of interaction, but children also stated using them in conjunction with other languages such as Dutch and Sranantongo, particularly in Paramaribo and eastern urban centers, and with other Maroon languages such as in the case of children interviewed in the district of Brokopondo. Fourth, Maroon languages, and Aukaans in particular, appear to also function as a peer group languages and/or a lingua franca nowadays. About 30\% of children in our sample stated using a Maroon language, typically Aukaans, predominantly with friends often in conjunction with either Nederlands and/or Sranantongo. Some of these children had a parent of Maroon cultural background, but more than half of them did not. This suggests that intergenerational transmission is no longer the only way to learn a Maroon language. At least some of the Maroon languages are now also learned outside of the family context, most typically through interaction with peers. The same has been already shown for western French Guiana where Aukaans or Ndyuka, as it is called there, is the language of interaction among schoolchildren and Aukaans and Sranantongo are widely used as lingua francas (Léglise 2004 and 2007; Léglise and Migge 2006; Migge and Léglise 2013). In Suriname, this is particularly apparent among children in the Brokopondo district and among some children in Paramaribo.

Finally, while Sranantongo is rarely cited as a first language and then usually in conjunction with Nederlands, it is used in a broad range of interactions such as in interactions with grandparents, siblings and peers. However, there is quite a bit of variation in usage patterns across children and regions. Some children only declare it as a language for peer group interactions while 
others report using it mostly with their parents and/or grandparents. Being Suriname's main vernacular, boys are more likely to align with Sranantongo than girls because its social connotations - as people usually declare-(peer solidarity, forthrightness, etc.) match up much better with local norms of boyhood: Only $4.5 \%$ of girls but $7 \%$ of boys claim Sranantongo as an $\mathrm{L} 1,23 \%$ of girls compared with $37.5 \%$ of boys claim it as an L2. When it is claimed as an L3 the differences are less stark: $33 \%$ of girls and $37 \%$ of boys claim Sranantongo as an L3. English is overwhelmingly claimed as an Li by children who either themselves or whose parents originate from Guyana. Some of the children said that they use only Engels with both or one of their parents while others reported using it in conjunction with Nederlands when interacting with their parents. Interactions with grandparents, if they were accessible, i.e. lived in Suriname, tended to be in Engels too, but in some cases they were also carried out in Nederlands. In interactions with siblings, and particularly friends, Nederlands and/or Sranantongo appear to dominate, however.

\section{Linguistic Ideologies}

Language ideologies have an important impact on patterns of language use. They have also been defined as "the cultural system of ideas about social and linguistic relationships, together with their loading of moral and political interests" (Irvine 1989b: 255). They are beliefs, or feelings, about languages as used in their social worlds" (Kroskrity 2006: 498). This includes beliefs about the superiority or inferiority of a given language (variety) or beliefs about the (in) appropriateness of a language (variety) in a certain situation or among certain groups of speakers. Language ideologies have to be conceived of as multiple because groups of people tend to be characterised by various degrees of heterogeneity and therefore typically involve different kinds of positionality and produce different kinds of perspectives on the same issue. In addition, members of social groupings do not tend to be homogeneous with respect to their awareness of local language ideologies. Language ideologies mediate between social structure and forms of talk, and play an important role in creating and representing social and cultural identities. They are always interested rather than neutral, serving the needs and ideas of specific social groups (Kroskrity 2006: 501-510).

An important finding of the survey was that children in Suriname considered using several languages in order to carry out their everyday activities to be the norm. None of the children who claimed several languages registered discomfort at being multilingual. Being multilingual was presented as both 
an asset and as a way of 'fitting in' and being able to connect with people. In contrast to that, a number of the children who reported using only one language - usually Dutch —often signaled unease about their monolingual status, even though they claimed the language with the highest overt prestige in the country. Respondents also displayed a favourable disposition to multilingualism in their responses to the question Are there any languages that you do not want to learn? Half of the children spontaneously responded with phrases such as I want to learn all languages or I like all languages rather than enumerating languages that they find undesirable. This can be taken as further evidence that knowing several languages is seen positively.

In addition to displaying a positive inclination to multilingualism, most of the children also asserted that they want to learn one or more languages that are not typically associated with Suriname. The same results were found in French Guiana (Léglise 2004), showing that international languages associated with the school context are widely presented as useful, suitable for learning and for preparing one's own future. Among these, Engels was the most frequently cited one, but Spaans, Portugees and Frans also figured on children's wish lists; a few children also mentioned other languages such as Chinees 'Chinese', Papiamento, Italiaans 'Italian' and Duits 'German'. The reasons for wanting to learn foreign languages varied depending on the language involved. English and Spanish, the two main foreign languages taught in Surinamese secondary schools, tended to be linked to educational achievement and access to prestigious jobs later in life and, in the case of English, to travel abroad and communicate with non-Surinamese people. Interest in English and to a certain extent in Portuguese was also spurred by more immediate needs such as the desire to better understand the English and Brazilian films that are regularly broadcast in their original version on Surinamese television. Desire to learn Portuguese and particularly French was often linked to the world of friends and family. In the case of Portuguese, children wanted to know more about their Brazilian peers while French was seen to be useful for communicating with people on trips to neighbouring French Guiana. Maroon children in particular expressed an interest in learning French because they were curious to find out more about one of the languages spoken by their French Guianese cousins, aunts and uncles. Some of the children also linked English to the family context suggesting that they wanted to learn it in order to stay in touch with family members who live abroad, usually the USA.

Children throughout the country also manifested their desire to learn English and the high esteem in which it is held in other ways. First, many children initially claimed it as being part of their linguistic repertoire while at the same time admitting that their competence is not high. Second, children often 
spontaneously rated it as the language that they like most and feel most comfortable with. Third, many children also asserted that they wanted to learn it better. English was also positively viewed among children who claimed it as (one of) their Lis. They stated using it in several interactional dyads, spontaneously selected it as their favourite language and overwhelmingly rated their competence as high. The only exception were $\mathrm{L} 1$ and L2 speakers of it who live in the western border town of Apoera. All of these children, who represented a clear majority of the children interviewed in that location, rated their competence negatively and expressed openly negative views about it. Given Apoera's proximity to Guyana and the fact that most of the children or their families originate from villages in Guyana, their rejection of the language might be linked to children's desire to assert difference to people from Guyana (and the village context) and positive alignment with Suriname.

In contrast to children's desire to learn so-called non-local languages, few children expressed an interest in learning so-called local languages. It is not entirely clear where this lack of enthusiasm for local languages stems from because children evidently learn languages other than the languages that they use in the home environment. One possible interpretation is that local languages are seen as lacking in social capital because it is Dutch and foreign languages like English that are linked to social advancement. Another possible contributing factor is that children may find the ethnic positioning conferred by certain languages and/or their link to tradition in general undesirable or simply incommensurate with their (current) social and/or ethnic alignments. Evidence in favour of this argument comes from children's responses to the question Which language (s) do you not want to learn? To take one example, a number of children supported their rejection of Hindoestaans with the following kinds of statements that highlight as problematic the ethnic positioning conferred by that language: this is not the language of my people, I don't belong to this ethnic group and they are different from me. Although desire to learn so-called local languages was weak, many children-when asked—registered an interest in learning to write their ancestral language(s) or their $\mathrm{Li}(\mathrm{s})$ if they were not Dutch. Several children also said that their parents were teaching them reading and writing in these languages suggesting that literacy in languages other than Dutch is valued.

The survey strikingly demonstrated that Dutch looms large in Surinamese children's imagination. It is not only the language that is most frequently cited, but children also did not have to be prompted about its use as children spontaneously reported having it in their linguistic repertoire. In fact, many children initially overstated their degree of usage, saying that they use it as their L1 
but on further questioning usually scaled down its importance for carrying out their daily activities. For instance, children who initially reported using Dutch and another language with their parents often 'admitted' using only a few words from Dutch in these interactions upon further questioning. Children also overtly asserted a positive disposition towards Dutch saying that they like using it either to the exclusion of other languages in their repertoire or as much as another language in their repertoire that they habitually use. This view is equally found among children living in Paramaribo as among those residing outside of the capital. Unlike the former, children living outside of Paramaribo typically rated their competence in Dutch as low and expressed a desire to learn it better. There are several reasons for the importance of Dutch in children's imagination. On the one hand, there is the fact that the survey was carried out through Dutch in one of the prime locations where it is habitually practiced and promoted, the school. On the other, it is the only language that children are accustomed to talking about in the public domain. Finally, association with Dutch in out-group formal kinds of settings carries positive association (sophistication, being part of modern urban society and for some, difference from the adult generation, see also Campbell 1983). ${ }^{21}$

In contrast to Dutch, Sranantongo appears to lack overt social prestige. Many of the children did not initially mention it when we asked them about the languages that they speak. Following further questioning, they confirmed using it, however, but acted as if there is no need to make this explicit. This might be taken to indicate that Sranantongo is an implicit or habitual language in Suriname. Children who stated using it (from the start) tended to link it to interactions with friends, siblings and in several cases also to interactions with fathers and older people. While a handful of children told us that their parents threatened them with corporal punishment for using Sranantongo and some girls, typically of Hindoestaan background, also expressed shock or offence at the idea of being associated with Sranantongo, most children did not voice overtly disparaging views about Sranantongo. Unlike Hindoestaan girls, particularly Javanese-Surinamese and Hindoestaan boys showed a strong desire to align with Sranantongo underscoring the fact that it has overtones of roughness, toughness and peer-group solidarity, which match up with local conceptions of young urban manhood. Finally, it is also interesting to note that relatively few children rated their competence in Sranantongo as low;

21 Note that Hellinga already concluded in 1955 that Creoles and Asians increasingly preferred Dutch to their ancestral languages. He argued that this was reflecting the changing socio-economic situation in the post-war period. 
TABLE 2.7 Children's self-assessment of their speaking competence in Sranantongo

\begin{tabular}{llll}
\hline & \multicolumn{3}{c}{ Sranantongo } \\
\cline { 2 - 4 } Reported speaking it: & Very good & Good & A little \\
\hline As an L1 & & & $26 \%$ \\
As an L2 & $48 \%$ & $26 \%$ & $33 \%$ \\
As an L3 & $43 \%$ & $24 \%$ & $42 \%$ \\
\hline
\end{tabular}

according to Table 2.7 only one third of children rated their competence in Sranantongo as low, a figure which is comparable to the results obtained for other languages, see below for Maroon languages, for instance. This confirms that Sranantongo is a widely used language in Suriname. Note, however, that less than half of the children rated their competence in it as very high; this figure is higher than for other 'ethnic languages'. The results from the survey do not allow us to conclude that Sranantongo currently functions as a symbol of a common Surinamese identity as suggested in some of the previous literature. It does, however, have a function that goes beyond simply linking people (lingua franca) because it, instead of Dutch, is used in political campaigning, joking and for doing 'truthful' or honest talk (e.g. criticism), suggesting that it expresses intra-Surinamese solidarity. Note, however, that this kind of solidarity function is ideologically much more strongly linked to men and particularly younger working-class urban men.

The social assessments of the other languages spoken in Suriname were variable across languages and also across speaker groups suggesting that it is not really possible to generalise across all ethnic or community languages. The differences in assessment patterns crucially dependent on a number of factors such as their speakers' role in the public life of Suriname, the historical development of the speaker communities and children's degree of knowledge and association with the languages and more crucially their speakers. This becomes very apparent when we compare views about Hindoestaans, Javanaans and Chinees, for instance. Children who stated speaking Hindoestaans as (one of) their L1s or as an L2 tended to assess their oral competence in it as good or very good suggesting a desire to align with the language. By contrast, children who said that they speak Javaans also said that they speak it only as a L2L4 and also overwhelmingly rated their competence as low, sometimes adding that they cannot properly communicate in it. Aside from actual degrees of competence, the low ratings strongly suggest that children do not want to 
strongly align with it - they are willing to 'admit' belonging to this social entity, but at the same time they are at pains to stress their difference to the traditional stereotypical image. Similar differences between the two languages emerge with respect to children's desire to learn to write Javaans and Hindoestaans. While a good number of the Hindoestaans-speaking children said that they want to learn to write Hindoestaans, there were very few Javanese-speaking children who wanted to do this. It is very difficult to determine Chinese speakers' alignment with the language, since only very few children claimed Chinese as a language that they speak. However, given the fact that very few children were willing to say that they speak Chinese may in itself suggest that overt alignment with it may not carry positive connotations. Additional qualitative research is necessary to determine why only a tiny minority of children interviewed stated speaking Chinese.

Views about the languages among others, i.e. languages that a speaker does not report as having it in their repertoire, were equally heterogeneous. Chinees and Hindoestaans were quite frequently cited by others as languages that they did not want to learn. Several children explained that this is so because they associated these languages with specific ethnic stances that are incommensurate with their own ("I'm not from that group"), did not like the language and/or their speakers ("It's not nice"), or because their speakers had been rude to them ("they scolded me"). In the case of Chinese, children often also said that they did not want to learn it because they thought it was too difficult. However, in contrast to Hindoestaans, there were also a number of children who wanted to learn it in part because it was perceived as difficult. Negative attitudes towards Hindoestaans have a long tradition in Suriname (see Speckman 1963) and anti-Chinese sentiments have also grown in recent years with the rise in Chinese immigration to Suriname (Tjon Sie Fat 2009b, this volume). In contrast to negative views about Hindoestaans and Chinees, the survey did not elicit negative views about Javanese. Neither those who said that they speak it nor non-speakers voiced any positive or negative attitudes about it. It simply does not appear to figure prominently in children's linguistic imagination.

The survey confirmed that attitudes to Amerindian languages are predominantly low (Carlin and Boven 2002: 42-43). First, they were typically very reluctant to mention any association with these languages. Even in village communities where all or most of the people are of Amerindian descent, children often only admitted having an Amerindian language in their repertoire after follow-up questioning. In a number of cases, competence in a specific Amerindian language only emerged when discussing the linguistic repertoires of grand-parents. Second, children generally rated their competence as low or non-existent. For example five out of ten children who cited Caraïbs as their 
first language and nineteen out of twenty-two children who cited Caraïbs and Arawaks as their second language declared that they spoke it only "a little". Third, children used the Dutch generalising term inheemse taal 'indigenous language' when referring to the language and some children did not provide a more specific name following further questions either because they wanted to avoid ethnic positioning or because they may not know it. Fourth, while a few children said that they would like to learn the language of their ancestors, several children who were not of Amerindian descent openly displayed contempt ("I don't like it"; "it's not nice"). Taken together, these responses strongly suggest that the children of Amerindian descent that we interviewed want to distance themselves from Amerindian languages.

In stark contrast to views about Amerindian languages, Maroon languages were rated quite favorably by both speakers and others. First of all, Table 2.8 shows that children who said that they speak a Maroon language generally rated their competence in it as good or very good.

Second, while only some children spontaneously asserted that they want to learn to write the Maroon language that they speak, many children showed an interest in learning to write in that language when directly asked. Third, the survey only elicited very few overtly negative views about Maroon languages. Only a handful of non-speakers said that they did not like a particular Maroon language (or its speakers), found it ugly or felt that its usage 'inhibits learning of Dutch'. Moreover, there were a few children who said that they would like to learn Aukaans. Interestingly, the survey also revealed some intra-Maroon issues. For instance, speakers of Matawai often held very low views about the closely related Saramaccaans and speakers of Saramaccaans and Aukaans did not always rate the respective other language all that positively, suggesting that they did not deem it desirable to learn it. It is clear that declared language practices function as symbolic boundary markers.

TABLE 2.8 Children's self-assessment of their speaking competence in Aukaans and Saramaccaans

\begin{tabular}{|c|c|c|c|c|c|c|}
\hline \multirow[b]{2}{*}{ Reported speaking it: } & \multicolumn{3}{|c|}{ Aukaans } & \multicolumn{3}{|c|}{ Saramaccaans } \\
\hline & Very good & Good & A little & Very good & Good & A little \\
\hline As an $\mathrm{L}_{1}$ & $63 \%$ & $18 \%$ & $19 \%$ & $68 \%$ & $9 \%$ & $19 \%$ \\
\hline As an $\mathrm{L}_{2}$ & $49 \%$ & $12 \%$ & $38 \%$ & $33 \%$ & $15 \%$ & $52 \%$ \\
\hline As an $\mathrm{L}_{3}$ and 4 & $50 \%$ & $15 \%$ & $34 \%$ & $50 \%$ & $25 \%$ & $25 \%$ \\
\hline
\end{tabular}


As highlighted in Section 3, naming conventions for lesser-used Maroon languages showed some variability. Although there are six Maroon languages spoken in Suriname, children mostly made reference to only two of them, namely Aukaans and Saramaccaans. While their speaker communities are by far the largest, lack of mention of the others may also be related to other factors. When comparing responses in the traditional territories with those received in the urban and coastal regions, it becomes apparent, for instance, that the names of smaller Maroon languages are regularly cited in the former but comparatively rarely in the latter. This suggests that speakers of lesser-used Maroon languages might be using the name of the most closely related dominant Maroon language (e.g. Aukaans instead of Paramaccaans) as a cover or generalising term to refer to their own language in order to either accommodate perceptions of the interviewer ("she probably does understand these difference") and/or in order to avoid ethnic positioning. Evidence in favor of the latter view is the fact that children often used names other than Aukaans (e.g. Ndyuka) in order to highlight a divergent (i.e. rural or traditional) variety. Thus by using the generalising term rather than a specific one, children might be projecting themselves as urban and/or modern Maroons.

While carrying out the survey, we also observed actual language practices in Suriname and made some recordings of such practices. ${ }^{22}$ Here we will mainly report on the broad findings. Although Surinamese people are bilingual or multilingual, observation of usage patterns clearly shows that language use patterns are socially stratified. While rural populations in general freely use local languages such as the Maroon languages and Sarnámi/Hindoestaans within the extended family unit and as community languages, Dutch seems to be enforced for children in Afro-Surinamese urban families and in middle class families in these settings. In the case of middle class families, there is reciprocal use of Dutch in interactions between children and parents and parents also use Dutch among each other to a large extent and sometimes to the exclusion of other languages. Other languages, especially Sranantongo, may though be used by the parents in heated exchanges and during scolding (see Garrett 2005 for St Lucia). In non-middle class families, parents require their children to speak Dutch to them, but they may, depending on competence, use another 
language to address them. These rules seem to be much more strictly enforced with girls than with boys especially in the case of Sranantongo because its social connotations do not easily match up with images of respectable womanhood. However, in several cases, women reported that they were expected to use Sranantongo roughly from the age of fourteen or at the onset of womanhood. If they did not speak it, or if they spoke it badly, they tended to be ridiculed by their elders and scolded for being arrogant. Especially in urban public contexts, addressing someone who is senior, unknown or whom the speaker wants to impress (e.g. flirting) in a language other than Dutch is likely to cause offence or rejection especially in public settings. People who are not fluent in Dutch at least use a few commonly used introductory phrases—greetings and introduction to the purpose of visit-in Dutch before proceeding to present the main issue in another shared language such as Sranantongo. This suggests that Dutch functions as a language of respect in Suriname.

Our observations also confirmed those of other researchers (e.g. Breinburg 1983; Carlin 2001) who found that language use in Suriname is rife with code alternation phenomena. People frequently alternate between two or more languages. They draw on an ancestral language and Sranantongo and/or Dutch in order to negotiate social relationships, types of settings and to invoke certain kinds of positive identities and or social alignments. Example (1) is a case in point. Here three men are interacting in the village context. $\mathrm{S}$ and $\mathrm{H}$ are in their late 6os and position themselves as leaders of the local village community while B is in his late 30 and tends to position himself as a modern sophisticated young man. In (1) they are discussing current affairs in the Maroon language Pamaka. ${ }^{23}$

(1)

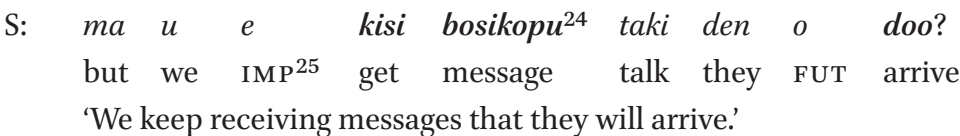

23 Bold: Eastern Maroon Creole; underlined: Sranantongo; italics: shared Eastern Maroon Creole and Sranantongo; italics and underlined: Dutch.

24 They are both articulated with a [S] rather than an [s], i.e. [kifi] which is indicative of Pamaka/Aluku.

25 DEM=Demonstrative; DET=determiner; $\mathrm{FUT}=$ future marker; IMP=imperfective marker; LOC=Locational preposition; NEG =Negation; PAST=past marker 
$\mathrm{H}$ : eyee, ma den án doo anda ete. yes but they NEG arrive over.there yet 'Yes, but they have not yet arrived there.'

B: omu, da fa waka anga a toli dati. no-wan uitleg no de! elder thus how walk with DET story DEM NEG-DET explain NEG there

Sani gaanman no man lusu, no-wan sani den kabiten thing chief NEG can loosen NEG-DET thing DET leaders

$\begin{array}{lllll}\underline{\text { no }} & \text { man } & \text { lusu } & \text { no-wan } & \text { sani? } \\ \text { NEG } & \text { can } & \text { loosen } & \text { NEG-DET } & \text { thing }\end{array}$

'Elder, then how about that story. We don't get any explanation! Can Gaanman not remove it [the problem] and the village leaders are they not able to do anything?'

S: mi ná e go a ini a toli moo. san mi be o du, I NEG IMP go LOC inside DET story anymore what I PAST FUT do

da mi be o laporteer den man na a busi. thus I PAST FUT report DET man LOC DET forest

'I don't try to interfere with these things anymore. What I would have done, I would have told the men to come to the gold-mining areas.' (PM 1-NSF)

While $\mathrm{S}$ and $\mathrm{H}$ are consistently using a monolingual and more traditional Pamaka style of speaking, B tends to code-mix with Sranantongo and to a lesser extent with Dutch, although he is well able to speak monolingual Pamaka. In this context, B's consistent use of what could be termed bilingual or mixed speech functions to display his language competence and underlines his cockiness vis-à-vis the two elders — people are generally told things, but especially younger people do not ask about information.

Bilingual speech in many ways embodies modern Surinamese ways of being while monolingual speech is linked to somewhat negative stereotypes such as being traditional and backward, particularly among younger people. In many cases, the ancestral language serves as the matrix language and elements from other languages - most typically Sranantongo and Dutch but also sometimes (Jamaican) English-are inserted into this frame. ${ }^{26}$ This leads to the emergence of new varieties. These kinds of code-mixed styles are common among

26 People in Suriname get acquainted with Jamaican English through popular music and Jamaican artists. 
younger people, especially young men, and function as in-group markers. They function to assert powerful modern identities and to dissociate oneself from negative ethnic and social stereotypes associated with the monolingual use of (some languages), see e.g. Migge (2007).

However, there are also cases where Dutch and/or Sranantongo play a much more important role. Take for instance the broadcasting sector or theatre productions. Especially in the case of discussion programmes and call-in shows, it appears that Dutch and Sranantongo have fused to a certain extent as both languages provide not only lexical material but also structural patterns. Further research is necessary to determine the structural makeup of such practices. We also observed what is often referred to as situational or unmarked code-switching where people changed the overall language of interaction depending on a range of factors such as topic, context and interlocutors. For instance, Sranantongo or other local languages were usually used for intimate or family-related issues and other topical issues and people switched to Dutch or Sranantongo to talk about work-related issues and topics. A case in point occurred during observation at the Maroon Radio station Koyeba in Paramaribo. Two Maroon women were discussing the content of a broadcast on Surinamese receipts in Eastern Maroon varieties - the language of the broadcast-but switched to Dutch when discussing procedural matters for the programme such as which part should come first, who will press which button when and how long each part of the programme would be. In another instance, a teacher who hitched a ride with one of the authors, the field worker for the survey and another person who was driving the car, consistently used Sranantongo with the driver, Dutch mixed with Sranantongo with the field worker and English mixed with Dutch when speaking with one of the authors although she was using a mix of an Eastern Maroon variety and Sranantongo to speak to the other two during the same conversation. Equally striking was the non-reciprocal code-switching that was observed in another context. For instance, in a mobile phone shop, the customer spoke in Sranantongo while the female shop assistant consistently responded in Dutch to assert a high status female identity. Issues around code-switching in Suriname require more detailed attention.

There is relatively little data available on language practices involving Sarnámi (Hindoestaans), Javanese, Amerindian languages, Brazilian Portuguese, Chinese. However, observation during three events at the Javanese cultural centre suggests that speakers of Javanese typically code-mix between Javanese, Sranantongo and Dutch if they use Javanese and that Javanese rather than Sranantongo or Dutch often functions as the 'embedded' language. That is, elements from Javanese are inserted into Dutch or Sranantongo-based 
structures. Sarnámi is also often used in a code-mixed fashion, but in this case, it is typically Sarnámi that functions as the matrix language and Dutch and Sranantongo as embedded languages. In urban 'working class' families Hindoestaans and Sranantongo are regularly used in the same context but also assigned different functions. By contrast, in middle class families it appears to be Dutch rather than Hindoestaans that is typically used and intergeneraltionally transmitted.

\section{$9 \quad$ Conclusion}

The first results of the language survey allowed us to assess existing descriptions of the linguistic landscape of Suriname in the literature and to add sociolinguistic detail to existing descriptions of the Surinamese landscape that tended to focus on historical usage patterns and on structural descriptive data (see Carlin and Arends 2002), and to update older descriptions (Charry et al. 1983). Our study showed that both multilingualism and plurilingualism are wide-spread in Suriname and that they are conditioned by a number of factors such as place of residence, ethnic alignment, social class, language ideologies and a host of contextual factors. Children who participated in the survey were generally happy to declare their linguistically diverse repertoires. While some languages such as Dutch and Sranantongo were frequently claimed by children all over the country, others, particularly Amerindian languages, were very little mentioned overall and yet others were primarily mentioned in some parts of the country, but not in others. The survey figures match up closely with census data for self-ascribed ethnicity categories in the case of some languages/ethnic categories and there are some mismatches with respect to others suggesting that especially in the main urban area, Paramaribo, membership in certain ethnic groups does not necessarily imply usage of and/or alignment with a particular ancestral language. This issue needs to be investigated in more detail based on qualitative data.

The survey also confirmed that languages in Suriname have different functional loads as they are used in different kinds of interactional contexts. However, most languages cannot be easily linked to only one or a small set of contexts because individual language use patterns show a fair amount of variability across different interactional dyads. For instance, in the case of many children, the official language of the country is no longer just associated with public and formal contexts, but is also frequently claimed as one of the languages for interactions with (some) family members and friends. However, the range of contexts or interactional dyads in which it is used, the degree of 
its usage in each context as well as attitudes towards it varied considerably among the children that were interviewed. The findings confirm that Dutch has become an integral part of the Surinamese way of life and of a modern Surinamese social identity. However, variability across individuals in the ways that they draw on it also suggests that there is no such thing as a monolithic Surinamese identity or that Dutch serves a unitary function in Suriname's multilingual and multicultural reality. More qualitative research is required to obtain a comprehensive understanding of the multiple functions that Dutch and Sranantongo serve. The survey also suggests that at least in terms of popularity, but maybe not in terms of actual competence, English is competing with Dutch.

Another important finding of the survey is that a number of the local languages continue to be valued and used by people in Suriname. While children voiced few overtly negative attitudes about any of the local languages, it is clear that they are assigned different social values. Some languages appear to be highly valued among their speakers (Maroon languages, Sarnámi), others appear to figure little in their speakers' imagination (Javanese, Amerindian languages, and maybe some forms of Chinese). While the use of a number of local languages is continuing and maybe even expanding in some cases, children's responses to our survey suggest that monolingual interactions are losing in importance; they appear to be increasingly associated with traditional ways of being. This finding in particular has important implications for research on the languages of Suriname since much of the research, following structural linguistic tenets, continues to focus on monolingual practices. The survey also highlighted that official, academic and lay conventions for naming languages do not always match up. In some cases there are important differences between them as in the case of Sarnámi and as in others, such as in the case of Sranantongo, they are quite heterogeneous. It is important to examine them carefully because they provide insights into people's conceptualisations of linguistic spaces (Léglise and Migge 2006, 2007; Migge and Léglise 2013).

The results of the survey provide a first detailed and empirically grounded overview of the linguistic situation of Suriname, including people's views about the languages spoken in the country. The findings suggest that while languages and language practices are still regionally differently distributed to a certain extent, rural-urban and cross-regional patterns of mobility among people, as well as participation in formal education continue to increase contact between languages that were previously not at all or only infrequently in contact. For instance, the official language is playing a more important role in rural areas and languages that used to be conceived of as 'tribal languages' are 
gaining ground in urban areas and are affecting urban practices. The languages of some neighbouring countries such as Brazilian Portuguese are gaining a foothold in the country, adding new dimensions to Suriname's multilingual and plurilingual realities. Greater social mobility has also led to greater access to and usage of Dutch-based practices throughout the country. It is no longer just the language of the elites, but is also available to and being used by others though arguably not always in the same ways. These processes have led to its greater social integration in Suriname as evidenced by the fact that all children acknowledge that it is part of their linguistic repertoire, but most likely greater social mobility has also given rise to a much greater range of types of practices. It appears that the question is no longer whether or not people speak Dutch, but how they draw on it and for what purposes. This needs further investigation.

The findings from the survey not only shine a light on the complexity of the linguistic landscape of Suriname but they also suggest that further qualitatively-oriented research is needed on issues such as

- the relationship between language and frequently invoked social categories such as ethnicity and social class in Suriname,

- the effects of mobility on language use,

- the effects of mediated language use in face-to-face interactions,

- the effects of multilingualism on language maintenance and

- the types of language contact patterns and their social and linguistic conditioning

in order to obtain an in-depth understanding of this context. 